\title{
Superelasticity and Shape Memory Behavior of NiTiHf Alloys
}

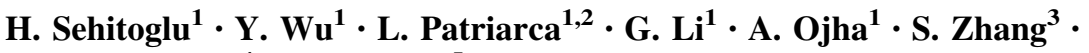 \\ Y. Chumlyakov ${ }^{4} \cdot$ M. Nishida ${ }^{5}$
}

Published online: 1 June 2017

(C) ASM International 2017

\begin{abstract}
The NiTiHf high-temperature shape memory alloys represent a significant advancement in extending the functionality of binary NiTi to elevated temperatures above $100{ }^{\circ} \mathrm{C}$. Despite this potential, the previous results in the literature point to a disappointingly low shape memory strains with addition of Hf. On the other hand, based on theoretical analysis using the lattice constants, the transformation strains should increase substantially with increase in Hf content. The present paper addresses this discrepancy, and using atomistic simulations, determination of twinning modes in martensite with transmission electron microscopy, digital image measurements of habit plane orientation, and strains in single-crystal specimens show that the experimental transformation strains in NiTiHf indeed increase with increasing $\mathrm{Hf}$ to unprecedented strain levels near 20\%. The Hf contents considered were in the range $6.25-25$ at. $\%$, and $\mathrm{NiTi}(0 \%$ Hf) results are provided as the baseline. The current work represents more than 60 experiments representing an
\end{abstract}

H. Sehitoglu

huseyin@illinois.edu

Y. Wu

yanwu7@illinois.edu

1 Department of Mechanical Science and Engineering, University of Illinois at Urbana-Champaign, $1206 \mathrm{~W}$. Green Street, Urbana, IL 61801, USA

2 Department of Mechanical Engineering, Politecnico di Milano, Via La Masa 1, 20156 Milan, Italy

3 Abbott Laboratories, Plymouth, MN 55311, USA

4 Tomsk State University, Tomsk, Russia

5 Department of Engineering Sciences for Electronics and Materials, Faculty of Engineering Sciences, Kyushu University, Kasuga, Fukuoka 816-8580, Japan extremely thorough study on single crystals and polycrystals.

Keywords Superelasticity - Shape memory effect . Electron microscopy $\cdot$ Transformation strain $\cdot$ NiTiHf

\section{Introduction}

\section{Historical Background}

NiTi alloys are the most widely used shape memory alloys (SMAs) due to their superior superelastic and shape memory behavior [1]. The NiTi possesses high transformation strains [2], low thermal and stress hysteresis [3], and good fatigue resistance [4]. The alloy has been a technological success with applications ranging from biomedical (mostly stents) to mechanical devices (such as actuators). Its behavior is well understood at the macro-level [5] and many issues at the micro-level are continuing to be investigated [6]. The NiTiHf alloys are relatively unexplored compared to NiTi, but have attracted considerable attention in the last 10 years [7-15]. The NiTiHf exhibits excellent slip resistance $[16,17]$ and high transformation temperatures [18]. At this stage, the basic SMA properties of NiTiHf are still being determined and the results are found to be highly dependent on many factors such as composition, (Ni/Hf contents), heat treatments, aging to generate precipitates, test temperatures, tension versus compression, and dislocation slip resistance [7-15]. Early works on transformation strains focused on the addition of $\mathrm{Hf}$ in the range 15-20 at.\% $[19,20]$ were insightful. In this study, we show the functionality of the new NiTiHf ternary alloys with $\mathrm{Hf}$ contents as high as 25 at.\%. 


\section{Insight into NiTiHf Alloys}

The calculations of the transformation strain for the binary NiTi have been published in early works and compared with experiments with good overall agreement [2, 21-24]. The highest transformation strains in binary NiTi have been observed as $10 \%$ in tension and $5.5 \%$ in compression. It is noteworthy that the theoretical transformation strains for NiTiHf are superior for both tension and compression compared to NiTi, while the asymmetry in tension-compression prevails. The strain increases linearly with $\mathrm{Hf}$ content [25], and so even small additions of Hf produce higher magnitudes of transformation strains. Since the NiTiHf transformation strains in compression can reach as high as $7 \%$ without the propensity of fracture, this can open up new applications. The tensile strains can reach near $15 \%$ which also exceeds the binary NiTi alloys (10\%) and can find specific uses. In this paper, we provide the calculations of the transformation strains for the NiTiHf SMAs with different $\mathrm{Hf}$ compositions (as high as 25 at.\%) to elucidate our point.

The use of the NiTi binary system is limited by its transformation temperature to below $75{ }^{\circ} \mathrm{C}$. To increase the transformation temperature of the alloy to above $120{ }^{\circ} \mathrm{C}$, ternary Hf elements can be added. With small additions of $\mathrm{Hf}$, the transformation temperature may not exhibit an observable increase; however, above 15 at.\% Hf, the transformation temperature changes becomes substantial and can reach $350{ }^{\circ} \mathrm{C}$. Other ternary elements have been attempted to raise TTs, but Hf provides the best mechanical properties $[7,10,18,19,26-33]$ such as slip resistance (>1 GPa) [16], reasonable cost (compared to $\mathrm{Pd}$ and $\mathrm{Pt}$ ). The range of $\mathrm{Hf}$ can vary from less than 10 to as high as 25 at. $\%$ and can elevate the transformation temperatures from 75 to $400{ }^{\circ} \mathrm{C}$. This increase can potentially open new applications.

\section{The Need for Present Work}

As stated above, previous papers postulated the potential niche role of NiTiHf alloys in the SMA field. Notwithstanding this promise, the experimental results of transformation strains fell considerably short of theoretical values by a factor of two to three in most cases. Most experiments on NiTiHf were conducted under compression, while it is known that the NiTi-based alloys exhibit higher strains in tension [34]. Therefore, we focus attention on tensile transformation strain cases in this paper to shed light into the difference between transformation strains from theory and experiment.

Based on previous works, valuable insight has been gained through many articles and reviews on the SMA metrics of the NiTiHf alloys [18]. More recently, the digital image correlation (DIC) technique is used which is an optical method of precise strain measurement by tracking the speckle patterns on specimen surfaces. The detailed procedures have been published elsewhere $[35,36]$. The DIC provides insight into the spatial nature of the transformation strains, and can pinpoint active martensite regions and untransformed (elastic) domains. With DIC, high transformation strain exceeding $10 \%$ were measured in our previous work $[37,38]$ close to theory. In this work, large collections of new experimental results (different heat treatments, tension/compression, and compositions) are summarized in master plots on the transformation strains as a function of crystal orientations. Examples of superelasticity and shape memory experiments under stress are also demonstrated outlining the potential of NiTiHf alloys in the result section.

\section{Overview of Previous Work and Background of SMAs}

In this work, we included the characterization of the new NiTiHf ternary alloys with three different chemical compositions, $\mathrm{Ni}_{50.5} \mathrm{Ti}_{36.2} \mathrm{Hf}_{13.3}, \mathrm{Ni}_{51.2} \mathrm{Ti}_{23.4} \mathrm{Hf}_{25.4}$, and $\mathrm{Ni}_{50.3-}$ $\mathrm{Ti}_{25} \mathrm{Hf}_{24.7}$ (at.\%). Because of better mechanical responses, the results of $\mathrm{Ni}_{50.5} \mathrm{Ti}_{36.2} \mathrm{Hf}_{13.3}$ and $\mathrm{Ni}_{50.3} \mathrm{Ti}_{25} \mathrm{Hf}_{24.7}$ were presented in the as-grown condition in "Experimental Results on NiTi13Hf and NiTi25Hf" section, while those of $\mathrm{Ni}_{51.2} \mathrm{Ti}_{23.4} \mathrm{Hf}_{25.4}$ alloys were shown in the aged condition $\left(550^{\circ} \mathrm{C}\right.$ for $\left.11 \mathrm{~h}\right)$. For the $\mathrm{Ni}_{50.3} \mathrm{Ti}_{25} \mathrm{Hf}_{24.7}$ alloy, the transformation temperatures measured from differential scanning calorimetry (DSC) are as follows: austenite start temperature $A_{\mathrm{s}}=251{ }^{\circ} \mathrm{C}$, the austenite finish temperature $A_{\mathrm{f}}=422{ }^{\circ} \mathrm{C}$, the martensite start temperature $M_{\mathrm{s}}=340{ }^{\circ} \mathrm{C}$, and the martensite finish temperature $M_{\mathrm{f}}=214{ }^{\circ} \mathrm{C}$. After aging at $500{ }^{\circ} \mathrm{C}$ for $4 \mathrm{~h}$, we found that the transformation temperatures are similar to those of the as-grown materials. The single crystal samples were cut from an ingot once the desired crystallographic directions are established. This was achieved by heating the samples to $500{ }^{\circ} \mathrm{C}$ to the fully austenitic state and conducting X-ray diffraction in the austenitic state on the single crystal ingots. For the $\mathrm{Ni}_{50.5} \mathrm{Ti}_{36.2} \mathrm{Hf}_{13.3}$ alloy, the transformation temperatures are much lower: $M_{\mathrm{s}}=-31.7^{\circ} \mathrm{C}$, $M_{\mathrm{f}}=-69.4{ }^{\circ} \mathrm{C}, A_{\mathrm{s}}=-14.8{ }^{\circ} \mathrm{C}$, and $A_{\mathrm{f}}=31.2{ }^{\circ} \mathrm{C}$. The $\mathrm{X}$-ray diffraction was used to orient these ingots as well, and then specimens were cut at desired orientations. In addition, the characterization of the superelasticity and shape memory effect of $\mathrm{Ni}_{51.2} \mathrm{Ti}_{23.4} \mathrm{Hf}_{25.4}$ (at.\%) has been investigated thoroughly in our previous studies [39], which will not be elaborated here. Based on our strain values procured for both $13 \mathrm{Hf}$ and $25 \mathrm{Hf}$ materials, a large database has been established to gain an insight into the comparison between the theoretical and experimental strain levels. 


\section{Outline of the Present Work}

To achieve a better understanding of these class of NiTiHf alloys, we undertake a comprehensive study that calculates the theoretical transformation strains in NiTiHf over a broad range of Hf contents and compare the results with our experiments on $13 \mathrm{Hf}$ and $25 \mathrm{Hf}$ contents. Previous experiments over the last 10 years have reported strains far less than $4 \%$ for the NiTiHf alloys, while the present work provides strain magnitudes that exceed $10 \%$ which is much closer to theoretical predictions. The previous experimental results were mostly in compression, and in the present study, we also focus on tension with much higher strains. We report the results of nearly 60 experiments with single crystals oriented in selected orientations. We found that [111] orientation is superior in tension to produce high transformation strains, while orientations near the [011] pole are more favorable in compression. The present work has focused on both superelasticity and shape memory (thermal cycling) experiments. Previous work has focused on temperatures less than $250{ }^{\circ} \mathrm{C}$, while in this work, our transformation temperatures are near $400{ }^{\circ} \mathrm{C}$ for the $25 \mathrm{Hf}$ composition.

The paper is organized as follows. (i) Firstly, we report the lattice constants determined via density functional theory (DFT) for 6.25, 12.5, and 25Hf compositions. Those of 15 and $20 \mathrm{Hf}$ materials from literatures have been included in this paper as well. A trend has been noted between monoclinic angles and Hf compositions. A comparison was made between the DFT results and those measured via TEM diffraction patterns for the $25 \mathrm{Hf}$ case. In addition, the microstructures of the samples with $25 \mathrm{Hf}$ have been characterized in this work as well. (ii) Secondly, the habit plane systems have been established for 6.25, 12.5, and $25 \mathrm{Hf}$ compositions. Based on the determined habit plane system, the theoretical calculation of the transformation (recoverable) strain for correspondent variant pair (CVP) formation and detwinned martensite for single-crystal NiTiHf has been undertaken. The prediction of the transformation strains using lattice deformation theory (LDT) was performed as well in this study. The similarity between the CVP + detwin strain and LDT strain is noted. These calculations pinpoint that the phase transformation favors more in [011] under compression and [111] under tension due to higher strain values near these poles. (iii) The superelastic response in [011] under compression and strain-temperature results under constant stress in tension for [111] orientation are presented for two Hf contents $(\sim 12.5$ and $25 \mathrm{Hf})$. The comparison of transformation strains from the experiments with LDT strain has been made. The polycrystal experimental results are also included for the two selected Hf contents and the theoretical strains are predicted based on the CVP formation, the grain orientations measured with EBSD and a micromechanical analysis.

Overall, this work provides a timely contribution to the understanding of the new NiTiHf SMAs with a wide range of $\mathrm{Hf}$ compositions (as high as 25\%) via comparisons between theoretical and experimental results. The good agreement between the two confers great potential in this class of materials. This work also highlights the need of a multifaceted approach, including (i) the DFT calculations, (ii) the TEM micrograph for characterizing microstructures, and (iii) the DIC measurement for pinpointing the spatial distribution of the strain contours, for the future SMA research.

\section{Results of the Present Work}

\section{Determination of Lattice Constants}

We consider alloys that follow the atomic composition $\mathrm{NiTi}_{50-x} \mathrm{Hf}_{x}$ with the Hf atomic content percentage $x$ ranging from 0 to 25 for DFT calculations. The six different alloys considered in this work and their lattice constants are plotted (Fig. 1). For the cubic to monoclinic transformation strain determination, the lattice constants include the cubic (B2) constant $a_{O}$ and monoclinic (B19') constants $a, b, c$, and the monoclinic angle. For the

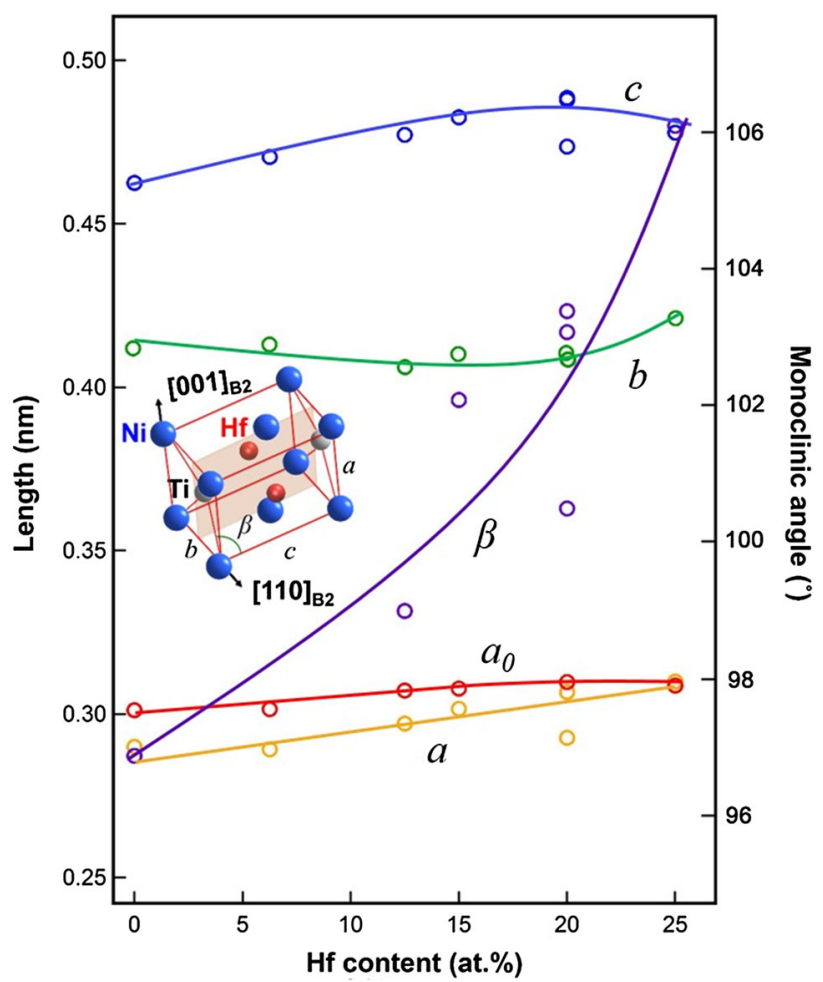

Fig. 1 The variation of the lattice parameters and the monoclinic angle with increasing $\mathrm{Hf}$ content. The lines are drawn to aid the eye 
monoclinic crystal structures, $c$ is the longest axis, $a$ is the shortest axis, and $b$ is intermediate in length. The monoclinic angle $(\beta)$ is the angle between the $a$ and $c$ axes. For an orthorhombic structure, the monoclinic angle would be $90^{\circ}$. For the $\mathrm{B} 19^{\prime}$ crystal, it increases from $97^{\circ}$ to $106^{\circ}$ with increasing $\mathrm{Hf}$, which is substantial.

The lattice constants in Fig. 1 for the $0 \% \mathrm{Hf}, 15 \% \mathrm{Hf}$, and $20 \% \mathrm{Hf}$ are obtained from experiments summarized in Table 1. The corresponding chemical compositions and principal investigators have been included as well. The designations HS, DH, HK, OB, and AS refer to Sehitoglu, Hodgson, Karaca, Benafan, and Stebner's work, respectively. For the $6.25,12.5$, and $25 \mathrm{Hf}$ cases, the lattice constants are obtained from DFT calculations ([16], Appendix 1 ), and we also confirmed the $25 \mathrm{Hf}$ lattice constants from the electron diffraction experiments in this study. The values of the experimental lattice constants have shown to differ depending on the investigator (for the 15 and $20 \mathrm{Hf}$ cases) but the increasing monoclinic angle with increasing Hf content is a common trend. Cubic (B2) to monoclinic $\left(\mathrm{B} 19^{\prime}\right)$ martensitic phase transformation occurs for alloys with Hf content in the range from 6.25 to $25 \%$. The energies of the orthorhombic (B19) and B19' phases are included as references (Appendix 1) showing the lower energy for the B19' lattice structure. The small energy difference between the two phases is noted, so these results do not preclude the possibility of B19 domains for the $25 \mathrm{Hf}$ case, but it is expected that B19' structure is dominant.

\section{Transformation Strains for CVP Formation}

During the phase transformation from austenite to martensite, the newly formed martensite crystal is internally twinned. The two twin-related martensite variants are called a correspondent variant pair, or CVP. As the phase transformation progresses, the twinned martensite crystal begins to experience detwinning, a process in which one variant within the CVP grows at the expense of the other [21]. We compute two values of transformation (recoverable) strains for single crystals. The transformation strain from the formation of CVPs is called the CVP formation strain, or simply the CVP strain. The transformation strain from the formation and detwinning of CVPs is called the CVP formation and detwinning strain, or simply the CVP detwinning strain $\left(\varepsilon_{\mathrm{CVP}}+\right.$ detwin $)$. Since $\varepsilon_{\mathrm{CVP}}+$ detwin includes both CVP formation and detwinning, it is an estimate of the total transformation strain. Another way to model the total transformation strain for single crystals is the lattice deformation theory (LDT) [43]. The LDT calculates the upper limit of the recoverable strain by assuming that austenite transforms into single crystal of martensite. Both the LDT strain $\varepsilon_{\mathrm{LDT}}$ and $\varepsilon_{\mathrm{CVP}}+$ detwin are calculations of the total transformation strain, and as expected, we show that a close correspondence exists between the two. LDT strains for [111] tension as a function of Hf content are shown in Fig. 2.

For NiTi and NiTiHf alloys, a number of different twinning modes may coexist in the martensite crystal during the phase transformation (Table 2). These modes of twinning are classified by their twin plane (interface plane between the variants in a CVP) normal $\mathbf{n}$ and twinning shear direction a. In Type I twins, the twin plane normal has rational indices. In Type II twins, the twin shear direction has rational indices. In compound twins, both the twin plane normal and twin shear direction have rational indices. Although the [011]-Type II is the predominant twinning mode in the binary NiTi alloy [22], the most frequently observed twinning modes for NiTiHf alloys with high Hf content are the (011)-Type I and (001) [001]Compound twins [32]. Therefore, the energy minimization calculations are focused on the (011)-Type I and (001) [001]-Compound twins for all alloys considered in this work. Two habit plane solutions are obtained as shown in Table 2 where the $\mathbf{m}$ and $\mathbf{b}$ designate the habit plane normal and habit plane shear, respectively. In the next sections, we explain the determination of the $\mathbf{a}, \mathbf{n}, \mathbf{b}$, and $\mathbf{m}$ and the computation of the CVP strain formation followed by lattice deformation calculations.
Table 1 A summary of the chemical compositions of the alloys from literature and current work

\begin{tabular}{lll}
\hline Material designation & Chemical composition (at.\%) & Principal investigator \\
\hline NiTi & $\mathrm{Ni}_{50} \mathrm{Ti}_{50}$ & [40]; HS [16] \\
NiTi6.25Hf & $\mathrm{Ni}_{50} \mathrm{Ti}_{43.75} \mathrm{Hf}_{6.25}$ & HS [16] \\
NiTi12.5Hf & $\mathrm{Ni}_{50} \mathrm{Ti}_{37.5} \mathrm{Hf}_{12.5}$ & HS [16] \\
NiTi13Hf & $\mathrm{Ni}_{50.5} \mathrm{Ti}_{36.2} \mathrm{Hf}_{13.3}$ & This study \\
NiTi15Hf & $\mathrm{Ni}_{49.8} \mathrm{Ti}_{35.2} \mathrm{Hf}_{15}$ & DH [9] \\
NiTi20Hf & $\mathrm{Ni}_{50.3} \mathrm{Ti}_{29.7} \mathrm{Hf}_{20}$ & HK [41]; AS [19]; OB [42] \\
& $\mathrm{Ni}_{49.8} \mathrm{Ti}_{30.2} \mathrm{Hf}_{20}$ & DH [9] \\
NiTi25Hf & $\mathrm{Ni}_{50} \mathrm{Ti}_{25} \mathrm{Hf}_{25}$ & HS [16] \\
& $\mathrm{Ni}_{51.2} \mathrm{Ti}_{23.4} \mathrm{Hf}_{25.4}$ & This study \\
& $\mathrm{Ni}_{50.3} \mathrm{Ti}_{25} \mathrm{Hf}_{24.7}$ &
\end{tabular}




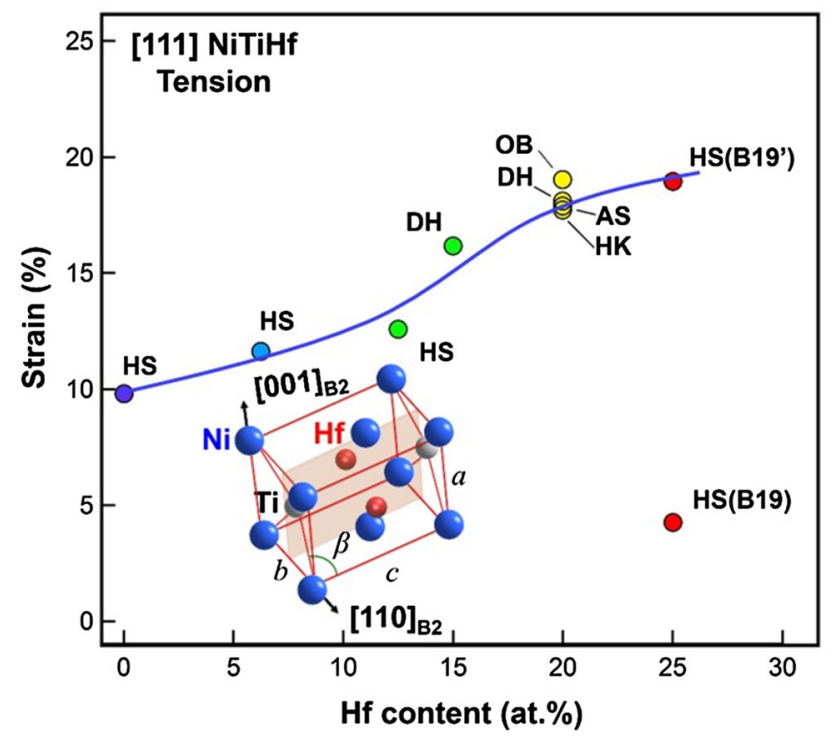

Fig. 2 The LDT strain for [111] single crystal under tension. The inset shows the monoclinic lattice. The lattice constants obtained from different investigators are marked with their initials

\section{CVP Formation and CVP Detwinning Strain}

The lattice orientations of the parent and twin phases are related through a number of different lattice correspondence variants. There are a total of 12 lattice correspondence variants for a cubic to monoclinic transformation, and six variants for a cubic to orthorhombic transformation. For each lattice correspondence variant, a deformation gradient tensor $\mathbf{F}$ and its symmetric part $\mathbf{U}$ can be determined. The components of the $\mathbf{F}$ and $\mathbf{U}$ matrices are functions of the lattice constants [22]. The lattice constants used in the calculations have been summarized earlier in Fig. 1. There are some differences in the constants for NiTi20Hf among DH, HK, OB, and AS, but the transformation strains calculated are rather close.

The kinematic compatibility between the two variants in the CVP across the twin plane requires that

$\mathbf{R}_{\mathbf{i j}} \mathbf{U}_{\mathbf{j}}-\mathbf{U}_{\mathbf{i}}=\mathbf{a} \otimes \mathbf{n}$

where $\mathbf{U}_{\mathbf{i}}$ and $\mathbf{U}_{\mathbf{j}}$ represent the $\mathrm{i}$-th and $\mathrm{j}$-th variants forming the CVP, $\mathbf{R}_{\mathbf{i j}}$ is an orthogonal rotation tensor between the two variants, $\mathbf{n}$ is the twinning plane normal, and $\mathbf{a}$ is the

Table 2 Twinning modes used in energy minimization calculations

\begin{tabular}{|c|c|c|c|c|c|}
\hline $\begin{array}{l}\text { Material } \\
\text { (investigator) }\end{array}$ & $\begin{array}{l}\text { Twinning } \\
\text { mode }\end{array}$ & $\begin{array}{l}\text { Twin plane normal } \\
(n)\end{array}$ & $\begin{array}{l}\text { Twin shear direction } \\
\text { (a) }\end{array}$ & Habit plane normal $(m)$ & Habit shear direction $(b)$ \\
\hline NiTi6.25Hf (HS) & (011)-Type I & $\left\{\begin{array}{llll}0.7071 & 0.7071 & 0\end{array}\right\}$ & $\begin{array}{l}<0.09090 .1382 \\
0.3323>\end{array}$ & $\begin{array}{l}\{-0.26750 .8514 \\
-0.4512\} \\
\{-0.84120 .0048 \\
0.5408\}\end{array}$ & $\begin{array}{l}<0.1111-0.0078 \\
\quad-0.0662> \\
<0.0417-0.1103 \\
0.0539>\end{array}$ \\
\hline NiTi12.5Hf (HS) & (011)-Type I & $\left\{\begin{array}{llll}0.7071 & 0.7071 & 0\end{array}\right\}$ & $\begin{array}{l}<0.04570 .1015 \\
0.3874>\end{array}$ & $\begin{array}{l}\{-0.23390 .9335 \\
-0.2718\} \\
\{-0.82360 .0888 \\
0.5602\}\end{array}$ & $\begin{array}{l}<0.1029-0.0181 \\
-0.0667> \\
<0.0350-0.1153 \\
0.0291>\end{array}$ \\
\hline NiTi15Hf (DH) & (011)-Type I & $\left\{\begin{array}{llll}0.7071 & 0.7071 & 0\end{array}\right\}$ & $\begin{array}{l}<0.03410 .1066 \\
0.4495>\end{array}$ & $\begin{array}{l}\{-0.10580 .9093 \\
\quad-0.4025\} \\
\{-0.9090-0.0045 \\
0.4169\}\end{array}$ & $\begin{array}{l}<0.1511-0.0115 \\
-0.0632> \\
<0.0297-0.1497 \\
0.0607>\end{array}$ \\
\hline NiTi20Hf (HK) & (011)-Type I & $\left\{\begin{array}{llll}0.7071 & 0.7071 & 0\end{array}\right\}$ & $\begin{array}{l}<0.01610 .1018 \\
0.4947>\end{array}$ & $\begin{array}{l}\{-0.06660 .9111 \\
\quad-0.4067\} \\
\{-0.9184-0.0168 \\
0.3952\}\end{array}$ & $\begin{array}{l}<0.1677-0.0118 \\
-0.0651> \\
<0.0270-0.1651 \\
0.0674>\end{array}$ \\
\hline NiTi25Hf (HS) & (011)-Type I & $\left\{\begin{array}{llll}0.7071 & 0.7071 & 0\end{array}\right\}$ & $\begin{array}{l}<0.01970 .0982 \\
0.4744>\end{array}$ & $\begin{array}{l}\{-0.01250 .8204 \\
\quad-0.5716\} \\
\{-0.9708-0.0709 \\
0.2292\}\end{array}$ & $\begin{array}{l}<0.2338-0.0060 \\
\quad-0.0390> \\
<0.0303-0.1953 \\
0.1310>\end{array}$ \\
\hline NiTi25Hf (HS) & $\begin{array}{l}\text { (001) [001] } \\
\text { Compound }\end{array}$ & $\left\{\begin{array}{lll}1 & 0 & 0\end{array}\right\}$ & $<0.01230 .22370>$ & $\begin{array}{c}\{-0.63480 .5926 \\
-0.4958\}\end{array}$ & $\begin{array}{l}<0.03570 .0316 \\
-0.0264>\end{array}$ \\
\hline
\end{tabular}


twinning shear direction. There is no summation of the index.

The kinematic compatibility between the twinned martensite and parent austenite requires that

$\mathbf{F}_{\mathbf{M}}-\mathbf{I}=\mathbf{b} \otimes \mathbf{m}$

where $\mathbf{I}$ is the identity tensor, $\mathbf{m}$ is the habit plane (interface plane between the twinned martensite and parent phase) normal, and $\mathbf{b}$ is the martensitic transformation shear. For a stack of thin twin layers, $\mathbf{F}_{\mathbf{M}}$ is defined by

$\mathbf{F}_{\mathbf{M}}=\mathbf{R}_{\mathbf{h}}\left(f \mathbf{R}_{\mathbf{i j}} \mathbf{U}_{\mathbf{j}}+(1-f) \mathbf{U}_{\mathbf{i}}\right)$

where $f$ and $1-f$ are the volume fractions of the two lattice correspondence variants, and $\mathbf{R}_{\mathbf{h}}$ is the relative rotation between the twinned martensite and the parent phase.

Substituting Eqs. (1) and (3) into Eq. (2),

$\mathbf{R}_{\mathbf{h}}\left(\mathbf{U}_{\mathbf{i}}+f \mathbf{a} \otimes \mathbf{n}\right)=\mathbf{I}+\mathbf{b} \otimes \mathbf{m}$

There are 84 equations in Eq. (4), which means that there are 84 sets of $(\mathbf{a}, \mathbf{n})$ in theory. However, some sets of lattice constants may not have all 84 solutions.

A symmetric matrix $\mathbf{C}$ is defined as

$\mathbf{C}=\mathbf{F}_{\mathbf{M}}^{\mathrm{T}} \mathbf{F}_{\mathbf{M}}$

Substituting for $\mathbf{F}_{\mathbf{M}}$ in terms of $f$, the matrix $C(f)$ can be rewritten as

$\mathbf{C}(f)=\left(\mathbf{U}_{\mathbf{i}}+f \mathbf{n} \otimes \mathbf{a}\right)\left(\mathbf{U}_{\mathbf{i}}+f \mathbf{a} \otimes \mathbf{n}\right)$

In order for Eq. (4) to have solutions, $C(f)$ must have ordered eigenvalues of $\lambda_{1} \leq \lambda_{2}=1 \leq \lambda_{3}$, which can be obtained from

$\operatorname{det}(\mathbf{C}(f)-\mathbf{I})=0$

Using the ordered eigenvalues $\lambda_{1} \leq \lambda_{2}=1 \leq \lambda_{3}$, the solutions of $\mathbf{b}$ and $\mathbf{m}$ are

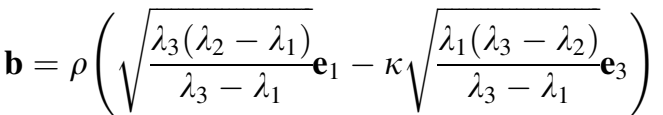

$\mathbf{m}=\rho^{-1}\left(\frac{\sqrt{\lambda_{3}}-\sqrt{\lambda_{1}}}{\sqrt{\lambda_{3}-\lambda_{1}}}\right)\left(-\sqrt{\lambda_{2}-\lambda_{1}} \mathbf{e}_{1}+\kappa \sqrt{\lambda_{3}-\lambda_{2}} \mathbf{e}_{3}\right)$,

where $\rho$ is a constant used to normalize the vectors and $\kappa= \pm 1$, which means Eqs. (8) and (9) represent two sets of $(\mathbf{b}, \mathbf{m})$. In theory, there are a total of 192 sets of $(\mathbf{b}, \mathbf{m})$, after taking solutions for both $f$ and $1-f$ into account. However, some sets of lattice constants may not have all 192 solutions for $(\mathbf{b}, \mathbf{m})$.

After having determined the sets of $(\mathbf{b}, \mathbf{m})$, the transformation CVP strain, $\varepsilon_{\mathrm{CVP}}$, can be calculated as

$\varepsilon=\frac{1}{2}\left(\mathbf{F}_{\mathbf{M}}^{\mathbf{T}} \mathbf{F}_{\mathbf{M}}-\mathbf{I}\right)$ $=\frac{1}{2}(\mathbf{b} \otimes \mathbf{m}+\mathbf{m} \otimes \mathbf{b}+(\mathbf{b} \cdot \mathbf{b}) \mathbf{m} \otimes \mathbf{m})$

To calculate the detwinning strain, the volume fraction $f$ is set to 0 if $f<0.5$. This changes the $\mathbf{F}_{\mathbf{M}}$ matrix from Eq. (3) to

$\mathbf{F}_{\mathbf{M}}^{\mathrm{dt}}=\mathbf{R}_{\mathbf{h}} \mathbf{U}_{\mathbf{i}}$

If $f>0.5$, then $f$ is set to 1 . In this case, the $\mathbf{F}_{\mathbf{M}}^{\mathbf{d t}}$ matrix is

$\mathbf{F}_{\mathbf{M}}^{\mathbf{d t}}=\mathbf{R}_{\mathbf{h}} \mathbf{R}_{\mathbf{i j}} \mathbf{U}_{\mathbf{j}}=\mathbf{R}_{\mathbf{h}} \cdot\left(\mathbf{U}_{\mathbf{i}}+\mathbf{a} \otimes \mathbf{n}\right)$

Using $\mathbf{F}_{\mathbf{M}}^{\mathrm{dt}}$, the total transformation strain (CVP formation and detwinning), $\varepsilon_{\mathrm{CVP}}+$ detwin, can be calculated in a similar way as Eq. (10), with $\mathbf{F}_{\mathbf{M}}$ being replaced by $\mathbf{F}_{\mathbf{M}}^{\mathbf{d t}}$.

\section{Lattice Deformation Theory Calculations}

The total transformation strain for single crystals can also be calculated using LDT. Unlike the energy minimization theory, LDT assumes that a single crystal of austenite transforms into a single crystal of martensite, without considering the effect of twinning. Therefore the total transformation strain is directly calculated using the deformation gradient tensor $\mathbf{F}$ [43, 44],

$\varepsilon_{\mathbf{L D T}}=\sqrt{\hat{\mathbf{e}} \cdot\left(\mathbf{F}^{\mathbf{T}} \mathbf{F e}\right)}-1$

where $\mathbf{F}$ is the deformation gradient tensor for a lattice correspondence and $\hat{\boldsymbol{e}}$ is the unit vector in the direction of the single crystal's orientation. There are 12 such correspondences in the cubic to monoclinic transformation, and all 12 are utilized to select the one that renders the highest strain.

Both $\varepsilon_{\mathrm{LDT}}$ and $\varepsilon_{\mathrm{CVP}}+$ detwin calculations yield essentially the same transformation strain values. LDT does not consider the intermediate processes of CVP formation, and considers transition from single crystal of pristine austenite to single crystal of martensite. Clearly, the calculations represent an ideal case because the presence of precipitates and slip domains at interfaces will result in a deviation from the ideal conditions.

The NiTiHf alloys with different Hf content are distinguished from one other in the transformation strain calculations by variations in lattice parameters. The lattice parameter that shows the most noticeable variation is the monoclinic angle, which displays a clear positive correlation with Hf content (Fig. 1). The LDT calculations are given in Figs. 3 and 4. The two most important orientations of interest are the [111] and [011] ones. The results show that with increasing $\mathrm{Hf}$ content, the transformation strains to rather high levels in tension and increase to moderately high levels in compression (Figs. 3, 4).

The transformation strains with increasing $\mathrm{Hf}$ content are given in the stereographic triangles in Figs. 4, 5, 6, and 


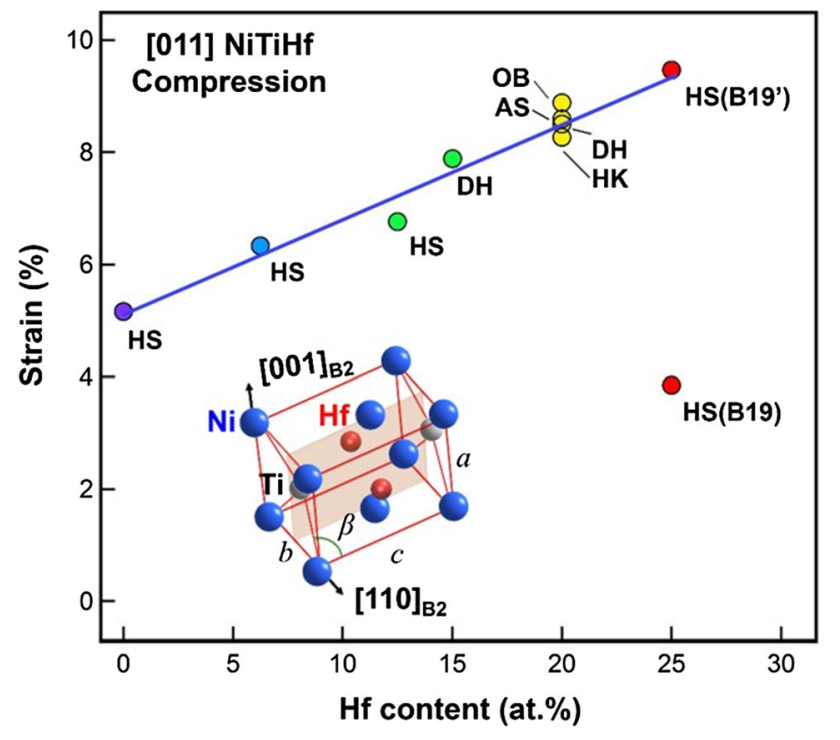

Fig. 3 The LDT strain for [011] single crystal under compression, the inset shows the monoclinic lattice for $25 \mathrm{Hf}$ composition. The lattice constants obtained from different investigators are marked with their initials
7. The maximum compressive $\varepsilon_{\mathrm{LDT}}$ increases to $11.5 \%$ for NiTi25Hf (for the [112] orientation). The maximum tensile $\varepsilon_{\text {LDT }}$ increases from $10.7 \%$ for NiTi (for the [774] orientation) to $19 \%$ for NiTi25Hf (for the [111] orientation).

For single crystals with [001] orientation, the compressive $\varepsilon_{\mathrm{LDT}}$ decreases with increasing $\mathrm{Hf}$ content. As the $\mathrm{Hf}$ content is increased, the crystal orientation of the maximum compressive $\varepsilon_{\text {LDT }}$ experiences a shift towards [112], which is closer to [011] than [001]. Therefore, the [001] pole experiences a decrease in compressive $\varepsilon_{\mathrm{LDT}}$ at higher Hf contents, while the [011] orientation experiences an increase in compressive $\varepsilon_{\mathrm{LDT}}$ at higher $\mathrm{Hf}$ contents. A similar pattern of a shift in the crystal orientation of the maximum strain is also present for the tensile $\varepsilon_{\mathrm{LDT}}$. For tensile $\varepsilon_{\mathrm{LDT}}$, the orientation of the maximum strain shifts from the [774] orientation for NiTi towards the [111] orientation for NiTiHf alloys with high Hf content (Table 3; Fig. 7). These shifts in the crystal orientation of the high transformation strains are ultimately caused by the changes in the lattice constants induced by the increase in $\mathrm{Hf}$
Fig. 4 The LDT strain contours for single crystals of $\mathrm{NiTi}$ and NiTi12.5Hf (cubic to monoclinic). We note the increase in transformation strains with addition of $\mathrm{Hf}$

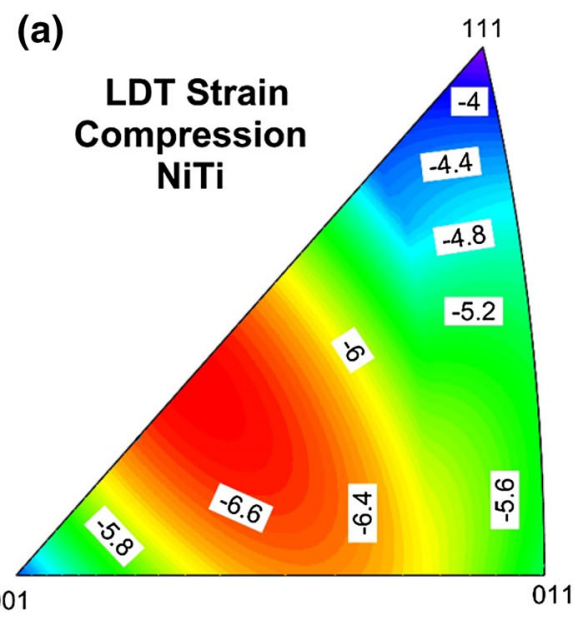

(c)

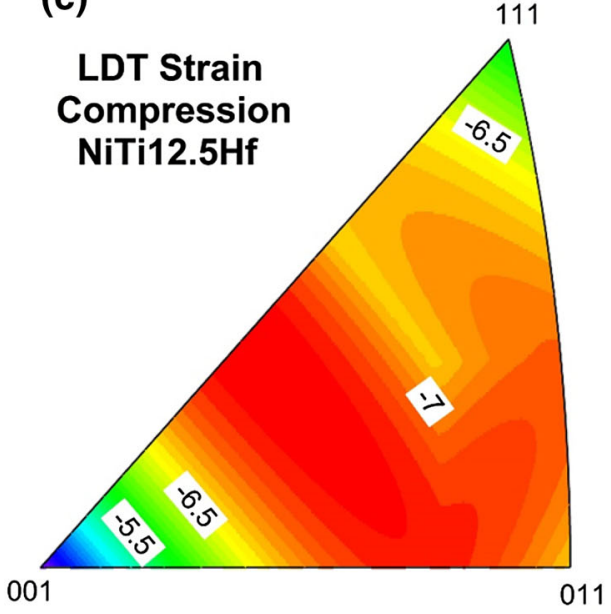

(b)

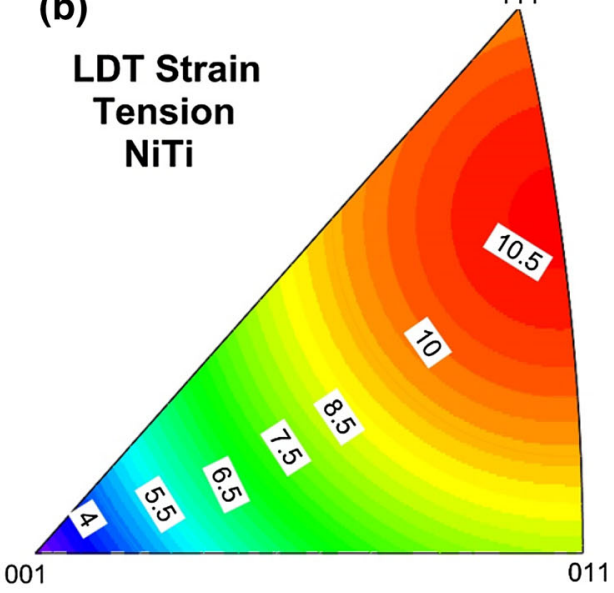

(d)

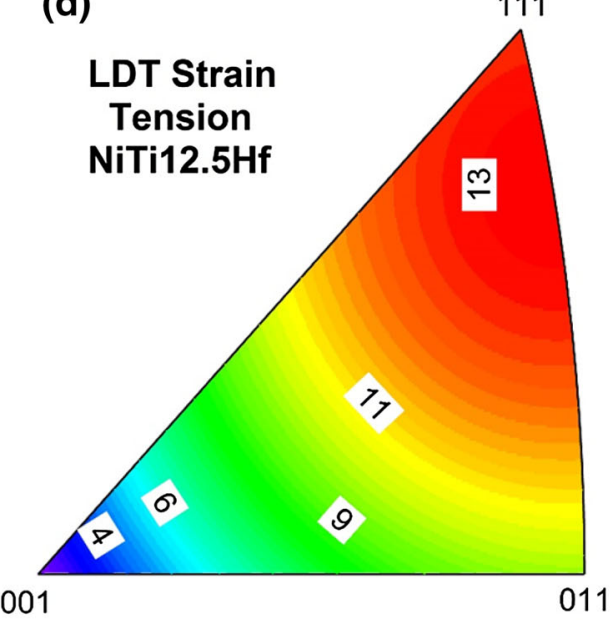


Fig. 5 The LDT strain contours for NiTi25Hf single crystals (cubic to monoclinic)
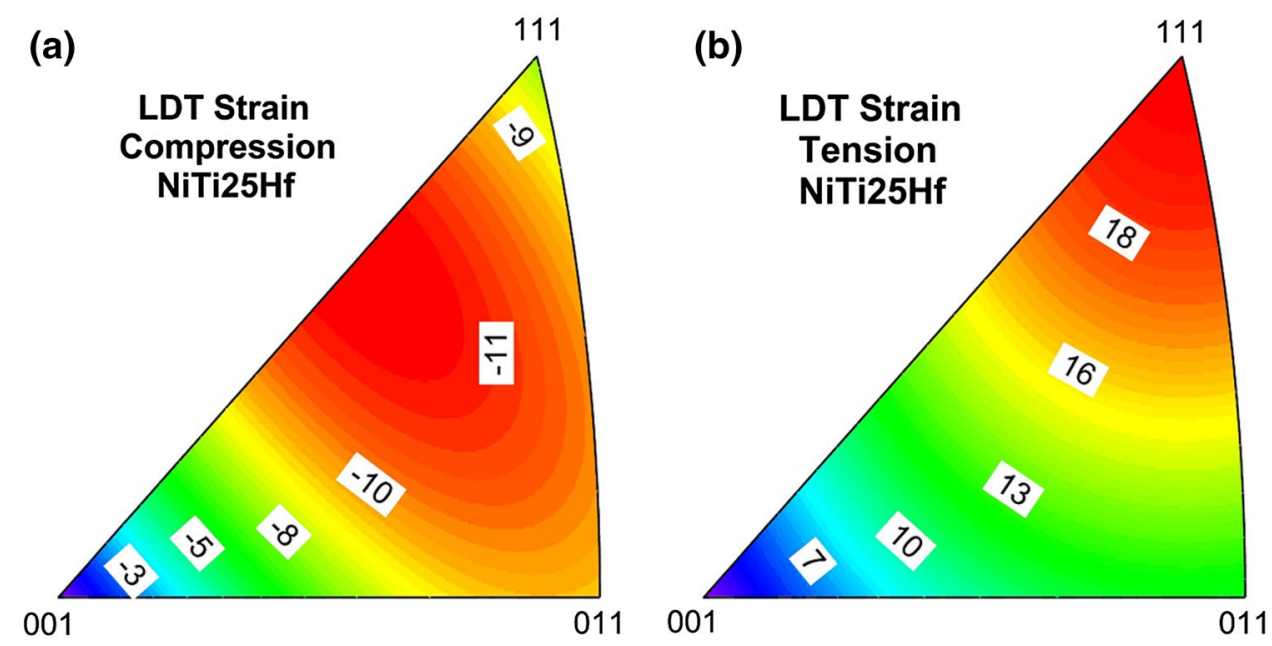

Fig. 6 [001]-Type II CVP strain contours for single-crystal NiTi; (011)-Type I CVP strain contours for single-crystal NiTi12.5Hf (cubic to monoclinic) for compression and tension. We note that the CVP formation strain is much lower than LDT strain in tension
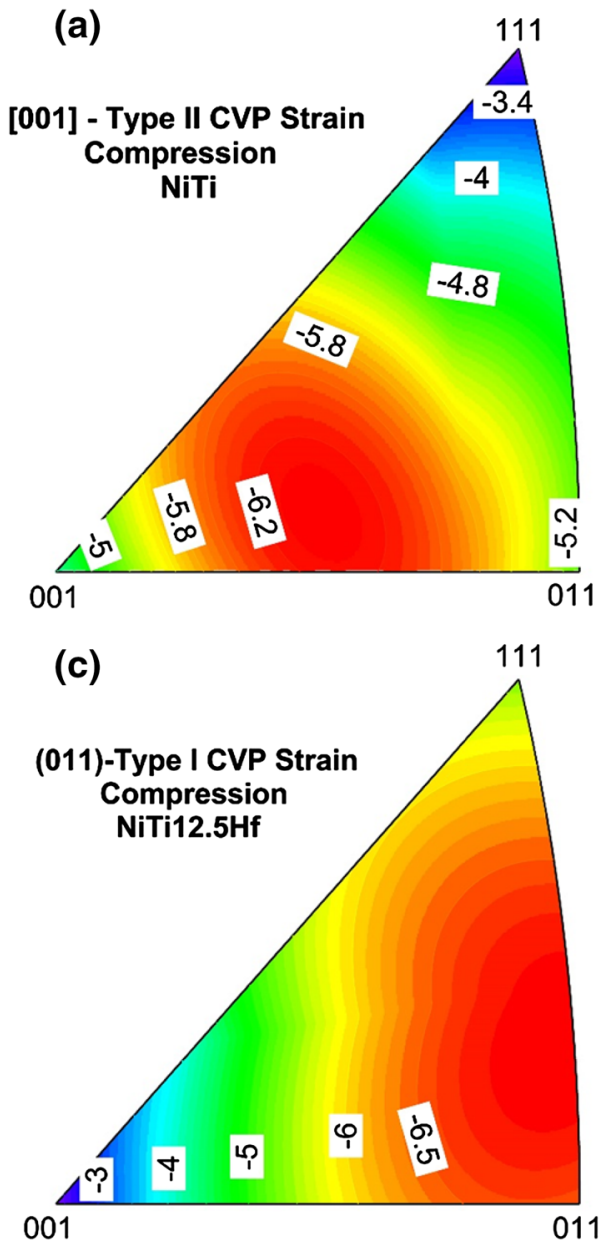
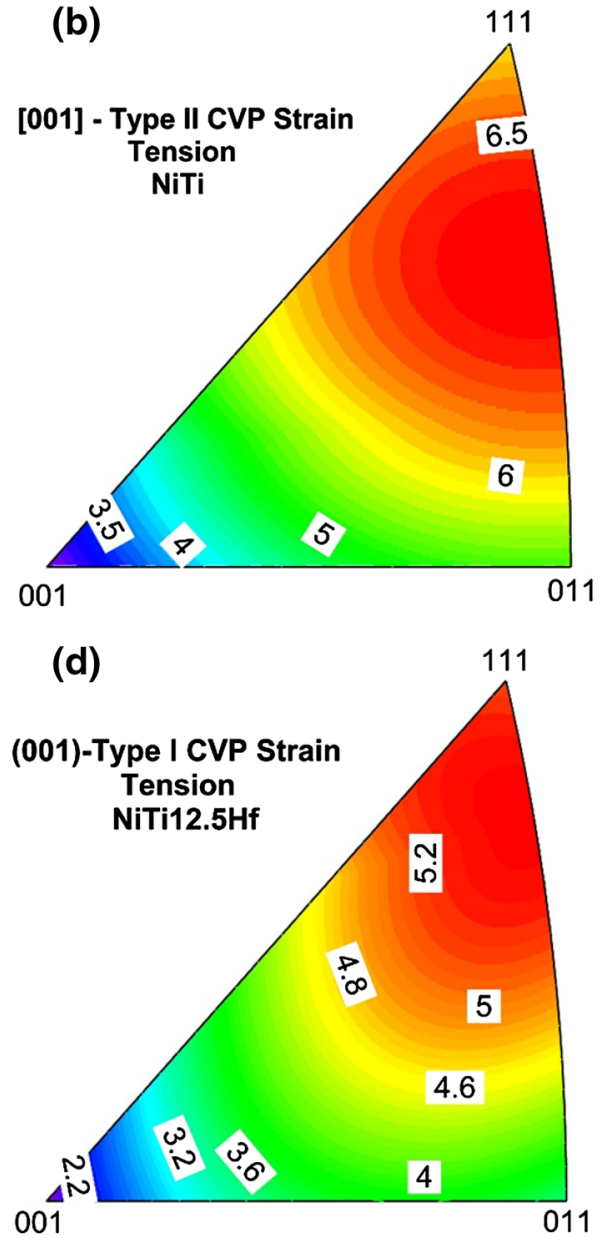

content, and most prominently the increase in the monoclinic angle.

The (011)-Type I twinning is of particular interest in this work, because it is generally the predominant mode of twinning in NiTiHf alloys [32]. Under compressive loading, the difference between (011)-Type I $\varepsilon_{\mathrm{CVP}}$ and
$\varepsilon_{\mathrm{CVP}}+$ detwin is very small. Under tensile loading, the difference is large (often $>40 \%$ ) for the (011)-Type I case. Overall, the model therefore predicts that the detwinning strain is much more significant for deformation under tension than under compression. 
Fig. 7 (011)-Type I CVP strain contours for single crystals of NiTi25Hf (cubic to monoclinic). The tension compression asymmetry of the transformation strains is noted
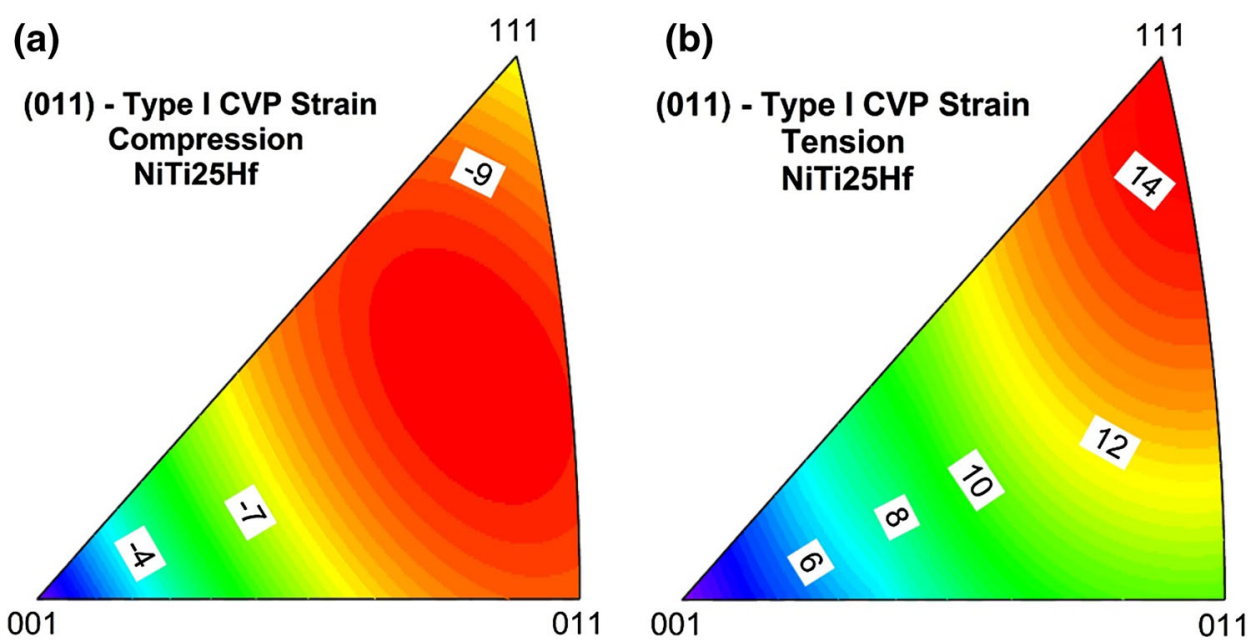

Table 3 Theoretical compressive transformation strains based on cubic to monoclinic model

\begin{tabular}{|c|c|c|c|c|c|c|c|c|c|}
\hline & \multicolumn{3}{|c|}{ [111] Single crystal } & \multicolumn{3}{|c|}{ [011] Single crystal } & \multicolumn{3}{|c|}{ [001] Single crystal } \\
\hline & $\begin{array}{l}\text { (011)-Type } \\
\text { I CVP strain } \\
(\%)\end{array}$ & $\begin{array}{l}\text { (011)-Type I CVP } \\
\text { and detwinning } \\
\text { strain }(\%)\end{array}$ & $\begin{array}{l}\text { LDT } \\
\text { strain } \\
(\%)\end{array}$ & $\begin{array}{l}\text { (011)-Type } \\
\text { I CVP } \\
\text { strain }(\%)\end{array}$ & $\begin{array}{l}\text { (011)-Type I CVP } \\
\text { and detwinning } \\
\text { strain }(\%)\end{array}$ & $\begin{array}{l}\text { LDT } \\
\text { Strain } \\
(\%)\end{array}$ & $\begin{array}{l}(011)- \\
\text { Type I } \\
\text { CVP } \\
\text { strain } \\
(\%)\end{array}$ & $\begin{array}{l}\text { (011)-Type I CVP } \\
\text { and detwinning } \\
\text { strain }(\%)\end{array}$ & $\begin{array}{l}\text { LDT } \\
\text { strain } \\
(\%)\end{array}$ \\
\hline $\begin{array}{r}\text { NiTi* (HS) } \\
\text { Type II-1 }\end{array}$ & 2.98 & 3.58 & 3.64 & 5.06 & 5.04 & 5.17 & 4.37 & 4.09 & 4.18 \\
\hline $\begin{array}{l}\text { NiTi6.25Hf } \\
\text { (HS) }\end{array}$ & 3.99 & 3.99 & 4.08 & 6.13 & 6.13 & 6.33 & 2.91 & 4.63 & 4.75 \\
\hline $\begin{array}{l}\text { NiTi12.5Hf } \\
\text { (HS) }\end{array}$ & 5.40 & 5.40 & 5.55 & 6.54 & 6.54 & 6.77 & 2.37 & 2.37 & 3.41 \\
\hline $\begin{array}{l}\text { NiTi15Hf } \\
(\mathrm{DH})\end{array}$ & 4.44 & 4.44 & 4.55 & 7.56 & 7.56 & 7.87 & 1.58 & 1.93 & 1.95 \\
\hline $\begin{array}{l}\text { NiTi20Hf } \\
\text { (HK) }\end{array}$ & 4.48 & 4.48 & 4.58 & 8.00 & 8.00 & 8.35 & 1.11 & 1.11 & 0.97 \\
\hline $\begin{array}{l}\text { NiTi20Hf } \\
\text { (OB) }\end{array}$ & 4.93 & 4.93 & 5.05 & 8.50 & 8.50 & 8.89 & 1.34 & 1.45 & 1.46 \\
\hline $\begin{array}{l}\text { NiTi20Hf } \\
\text { (DH) }\end{array}$ & 4.04 & 4.04 & 4.90 & 7.93 & 7.93 & 8.28 & 1.18 & 1.18 & 0.97 \\
\hline $\begin{array}{l}\text { NiTi20Hf } \\
\text { (AS) }\end{array}$ & 4.70 & 4.70 & 4.82 & 8.17 & 8.17 & 8.53 & 1.36 & 1.36 & 1.29 \\
\hline $\begin{array}{l}\text { NiTi25Hf } \\
\text { (HS) }\end{array}$ & 7.55 & 7.55 & 7.86 & 9.01 & 9.01 & 9.46 & 0.291 & 0 & 0 \\
\hline
\end{tabular}

Note that orientations near [011] pole produce strains as high as $9.5 \%$ in compression for NiTi25Hf

* CVP strain and CVP detwinning strain for NiTi are for [001]-Type II twin

\section{Determination of Twinning Mode with TEM}

Figure 8 shows typical selected area electron diffraction pattern (SAEDP) taken from NiTi25Hf aged at $500{ }^{\circ} \mathrm{C}$ for $4 \mathrm{~h}$ along $[110]_{\mathrm{B} 19^{\prime}}$, which corresponds to $\left\langle 111>_{\mathrm{B} 2}\right.$. There are nine sets of reflections, i.e., $3(001)_{\mathrm{B} 19^{\prime}}$ compound twinrelated martensites, and three precipitate variants. They can be consistently indexed by lattice parameters of monoclinic martensite: $a=0.309, b=0.421, c=0.478 \mathrm{~nm}$, and $\beta=105.9^{\circ}$, and orthorhombic precipitate (H-phase): $a=1.264, b=0.882$, and $c=2.608 \mathrm{~nm}$, respectively.

Morphological and crystallographic aspects of martensitic and precipitate phases are presented in Fig. 9. Figure $9(\mathrm{a}, \mathrm{b})$ shows the bright-field (BF) image and 
corresponding SAEDP, respectively. The details of SAEDP have been discussed in Fig. 8. There are fine striations less than $5 \mathrm{~nm}$ and particles about $10 \mathrm{~nm}$ in diameter with dark contrast in (a). The striations are clearly visualized in each of dark-field images in Fig. 9(c-e) taken using DF1-3 reflections in (b), respectively. The SAEDP and dark-field (DF) images suggest that there are 3 habit plane variants M1-M3 consisting of $(001)_{\mathrm{B} 19^{\prime}}$ compound twins in the

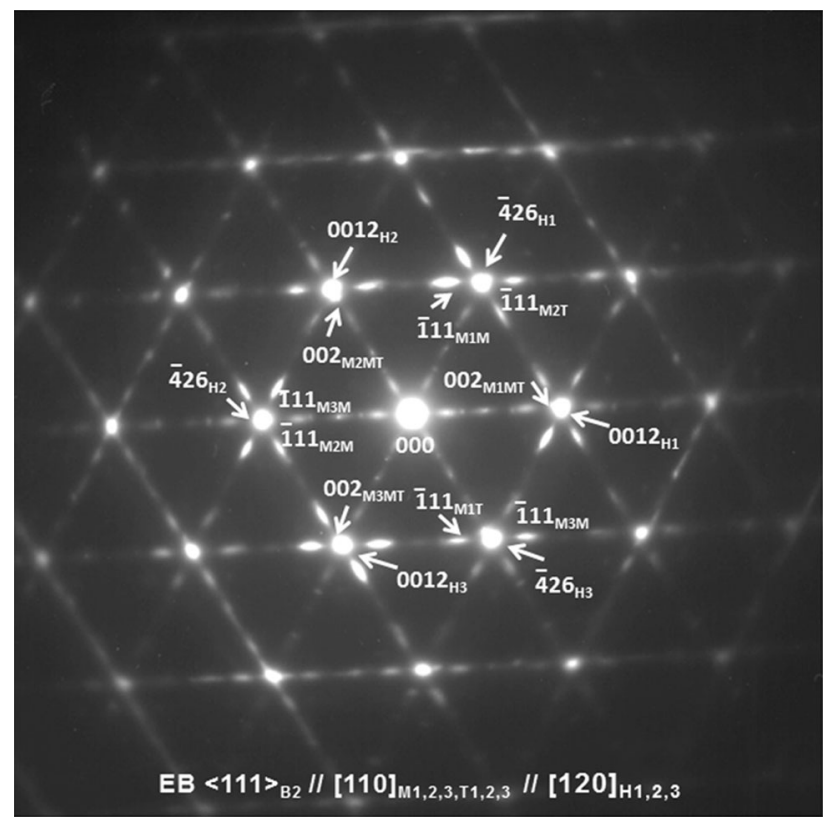

Fig. 8 Typical SAEDP taken from NiTi25Hf aged at $500{ }^{\circ} \mathrm{C}$ for $4 \mathrm{~h}$ along $[110]_{\mathrm{B} 19^{\prime}}$. The lattice constants obtained match the DFT calculations. $a=0.309, b=0.421, c=0.478 \mathrm{~nm}$, and $\beta=105.9^{\circ}$ (see Appendix 1)

Fig. 9 a BF image and b corresponding SAEDP taken from NiTi25Hf aged at $500{ }^{\circ} \mathrm{C}$ for 4 h. c-f DF images taken using DF1-4 reflections, respectively observed area. The twinning mode of the martensite is again discussed later. The interface between habit plane variants is very complicated in comparison to that in the solution-treated NiTi binary system [45]. The similar martensite morphology has been observed in aged Ni-rich NiTi binary alloy including fine $\mathrm{Ni}_{4} \mathrm{Ti}_{3}$ precipitates [46] The size of precipitate, i.e., H-phase, is about $10 \mathrm{~nm}$ as mentioned above. It is noteworthy from the DF image in Fig. 9(f) that the H-phase in NiTi25Hf has block shape rather than lenticular one in low Hf content alloys [28, 39].

Figure 10 shows SAEDP taken from NiTi25Hf aged at $500{ }^{\circ} \mathrm{C}$ for $4 \mathrm{~h}$ along $[100]_{\mathrm{B} 19^{\prime}}$, which is parallel to $<100>_{\mathrm{B} 2}$. The pattern consists of eight sets of reflections, i.e., $2(011)_{\mathrm{B} 19^{\prime}}$-Type I twin-related martensites and four precipitate variants. They can be also consistently indexed by lattice parameters of monoclinic martensite and orthorhombic precipitate, respectively.

Figure 11(a, b) shows the bright-field (BF) image and corresponding SAEDP, respectively. The details of SAEDP are discussed in Fig. 10. There are alternated platelets about $10 \mathrm{~nm}$ or less in width and particles about $10 \mathrm{~nm}$ in diameter with dark contrast in (a). The platelets are clearly visualized in each of dark-field images in Fig. 11(c-e) taken using DF1-3 reflections in (b), respectively. The SAEDP and dark-field images suggest that there are two habit plane variants M1 and M2 consisting of $(011)_{\mathrm{B} 19^{\prime}}$ Type I twins in the observed area. DF image in Fig. 11(f) is out of BF image where the Bragg condition is slightly not satisfied. However, precipitates are clearly visible. The shape and size of precipitate are similar to those in Fig. 9, although the incident electron beam is different. This also suggests that the shape of precipitate is blocky rather than
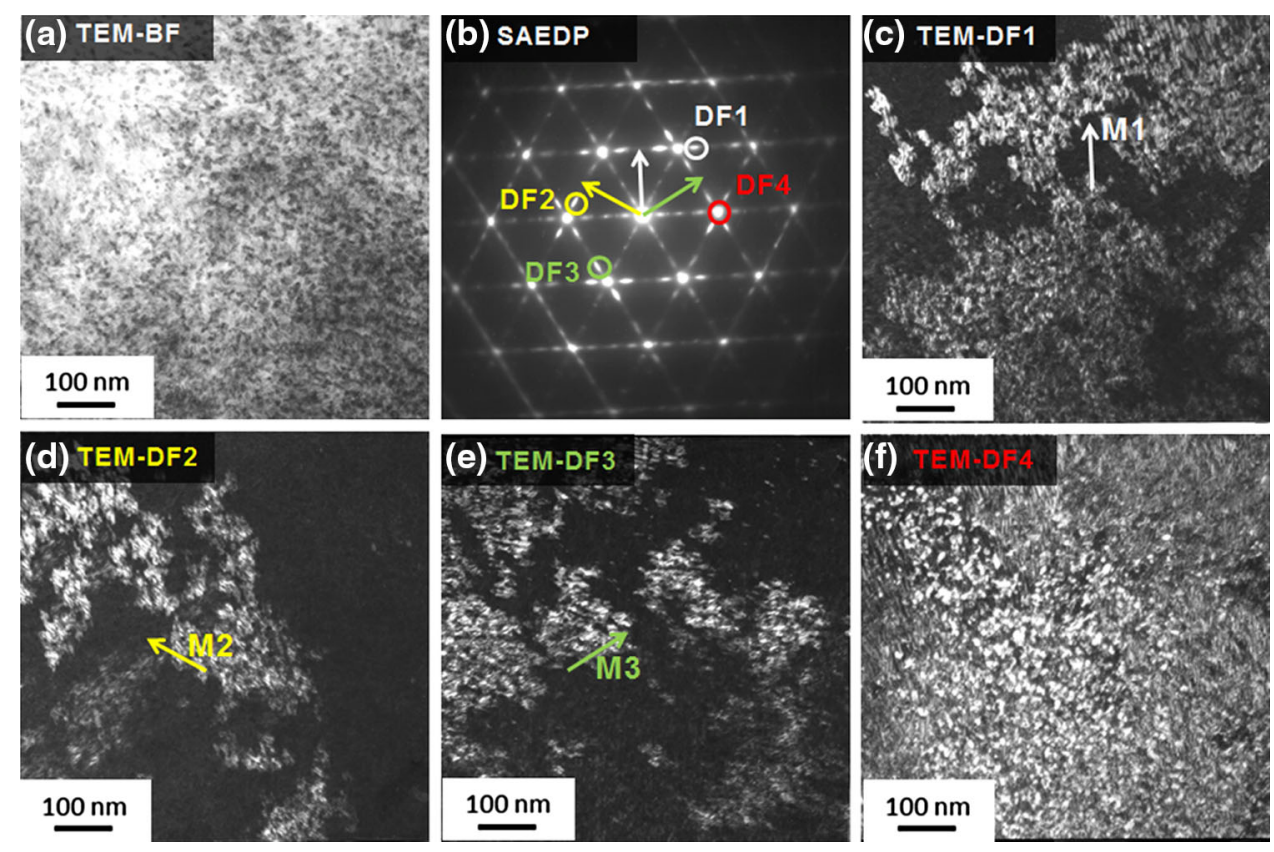
lenticular. From these observations, it is concluded that there are $(001)_{\mathrm{B} 19^{\prime}}$ compound twins in (011) Type I twin plates. The same situation has been observed in NiTi12.5Hf alloy [28]. We have further illustration of the presence of (011) Type I twin plates and $(001)_{\mathrm{B} 19^{\prime}}$ compound twins in the solutionized case in Fig. 12(a-d) because the calculations for the transformation strains assume solutionized conditions. Therefore, it is important to confirm that there is no change between the aged and

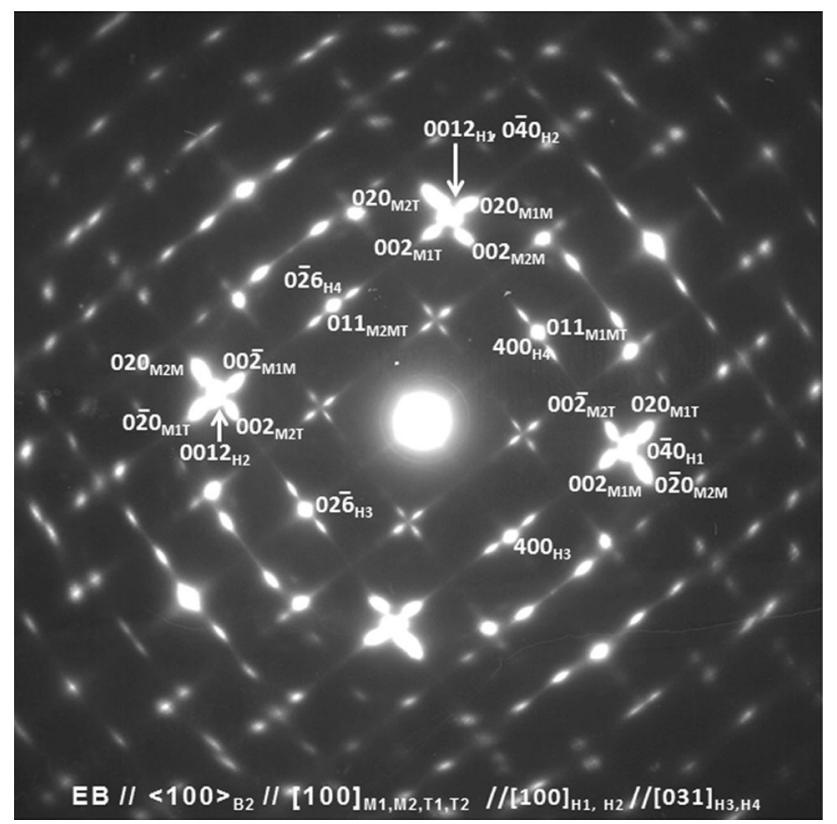

Fig. 10 SAEDP taken from NiTi25Hf aged at $500{ }^{\circ} \mathrm{C}$ for $4 \mathrm{~h}$ along $[100]_{\mathrm{B} 19^{\prime}}$

Fig. 11 a BF image and b corresponding SAEDP taken from NiTi25Hf aged at $500{ }^{\circ} \mathrm{C}$ for $4 \mathrm{~h}$. c-f DF images taken using DF1-4 reflections, respectively solutionized case in terms of the twin system. Figures 12 and 13 show the existence of (011) Type I and (001) compound twins, respectively. The corresponding electron diffraction patterns can be consistently indexed by lattice parameters of monoclinic martensite: $a=0.309$, $b=0.421, c=0.478 \mathrm{~nm}$, and $\beta=105.9^{\circ}$.

\section{Experimental Results on NiTi13Hf and NiTi25Hf}

We provide a summary of our experimental results for the $13 \mathrm{Hf}$ and $25 \mathrm{Hf}$ cases that have not been published in our previous studies in Figs. 14, 15, 16, and 17. In Fig. 14, the results show the superelasticity of the $13 \mathrm{Hf}$ alloy exhibiting strains exceeding $6.5 \%$ for [111] orientation in compression. The DIC images are depicted at locations 1 and 2 of the stress-strain curve. The strains are fully recovered upon unloading. The DIC results can be used to define a local and global strain measure. As noted in the insets in Fig. 14, there are elastic domains that do not transform. The local measure of strain represents the intrinsic transformation strain without the influence of the elastic domains. Such high strains in compression exceed previously reported values. We note that the stress magnitudes are as high as $1500 \mathrm{MPa}$ which can open new application for this alloy.

In Fig. 15, the results are shown for isobaric experiments for the $13 \mathrm{Hf}$ for [111] orientation in tension. The temperature is cycled under constant stress. The strain levels exceeded $13 \%$ in tension which are higher than previously reported experimental levels in binary NiTi [21, 47]. As stated earlier, small increases in Hf can result in considerable elevation of the transformation strain.
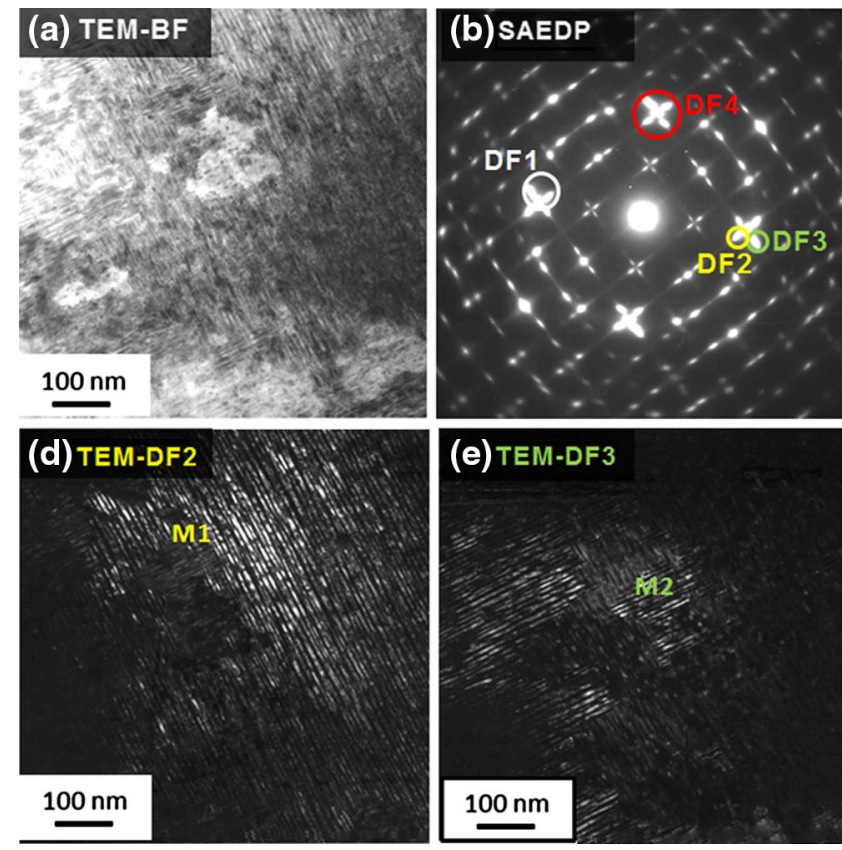

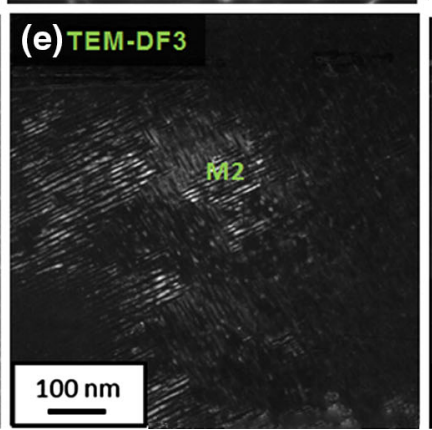

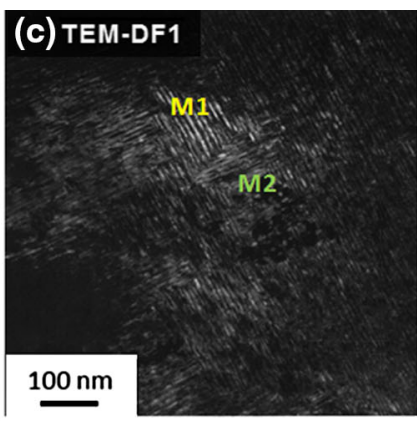

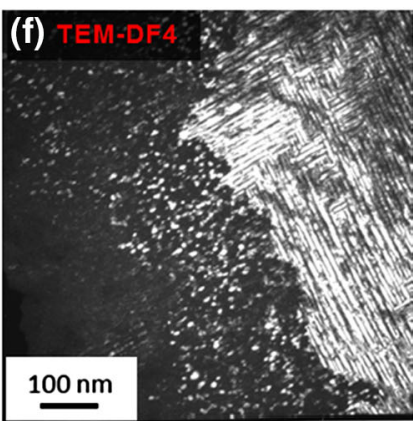




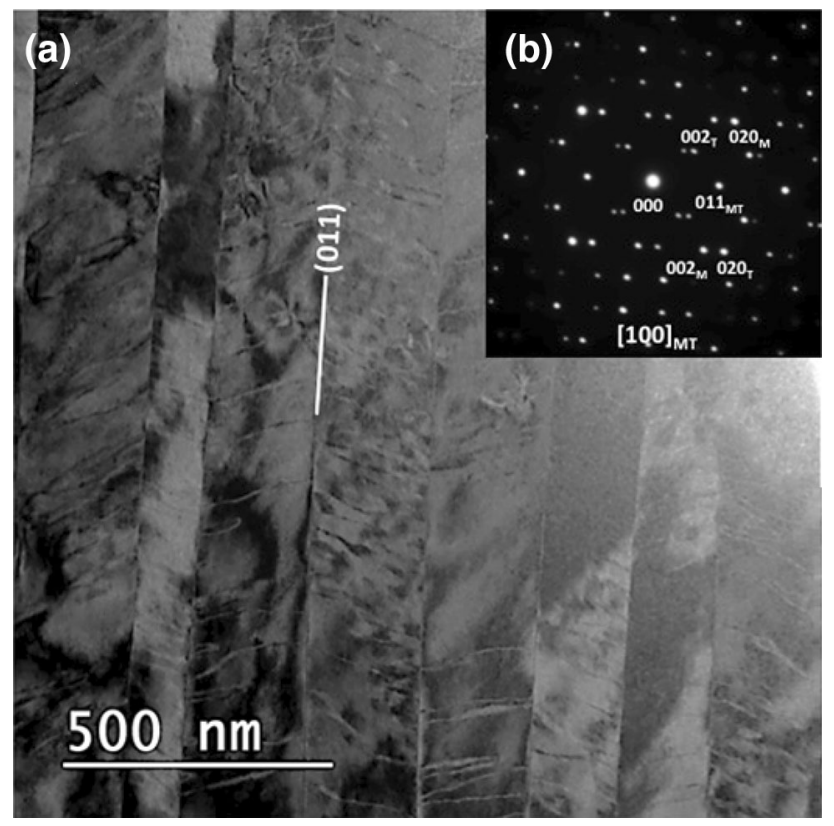

Fig. 12 a The TEM image and $\mathbf{b}$ the corresponding SAEDP taken form a solutionized specimen showing the activation of the (011) Type I twin plates

In Fig. 16, the compressive superelastic response of the high Ni content NiTi25Hf single crystals orientated along [011] direction has been shown at $200{ }^{\circ} \mathrm{C}$. The specimen was aged at $550{ }^{\circ} \mathrm{C}$ for $11 \mathrm{~h}$. The transformation strain of the order of near $3 \%$ locally has been shown under the overaged condition.

The tensile experimental result for the low $\mathrm{Ni}$ content NiTi25Hf alloys is shown in Fig. 17 under temperature cycling. Both local and global strains are shown, and the transformation strain in tension is nearly $10 \%$. The remarkable observation is that the $A_{\mathrm{f}}$ exceeds $400{ }^{\circ} \mathrm{C}$. In Fig. 17(b), we compare the traces of the habit planes as evident from the strain localization with the variants predicted from the phenomenological theory. The habit planes

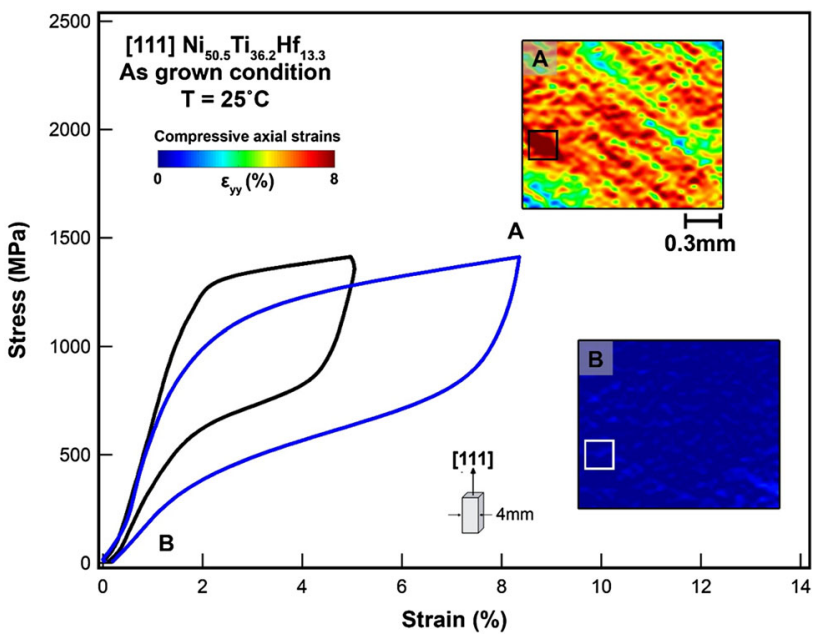

Fig. 14 The stress-strain response of NiTi13Hf under compression ([111] orientation). The dashed line corresponds to average strain over a smaller area shown above

associated with variants \#3, \#11, and \#9 coincide with the austenite/martensite interfaces that are noted in the DIC images below. The variants \#3, \#9, and \#11 belong to the habit plane family given in Table 2 as $\{-0.01250 .8204$ $-0.5716\}$. Note that we are only showing 12 out of 24 variants for brevity. In summary, the in situ measurements of $\mathrm{A} / \mathrm{M}$ interface orientations as reported here showed excellent agreement with the phenomenological theory lending support to our transformation strain calculations.

\section{Comparison of Experimental Results and Theoretical Results}

A compendium of the experimental results and the theoretical predictions are shown in Figs. 18 and 19. The experimental results are given for NiTi13Hf and NiTi25Hf single and polycrystals. The experimental results are compared with theory for a number of single-crystal
Fig. 13 a The TEM Image displaying the (011) Type I twin plates, and $\mathbf{b}$ the presence of compound (001) twins within the (011) Type I twin plates, and (c) corresponding SAEDP pattern
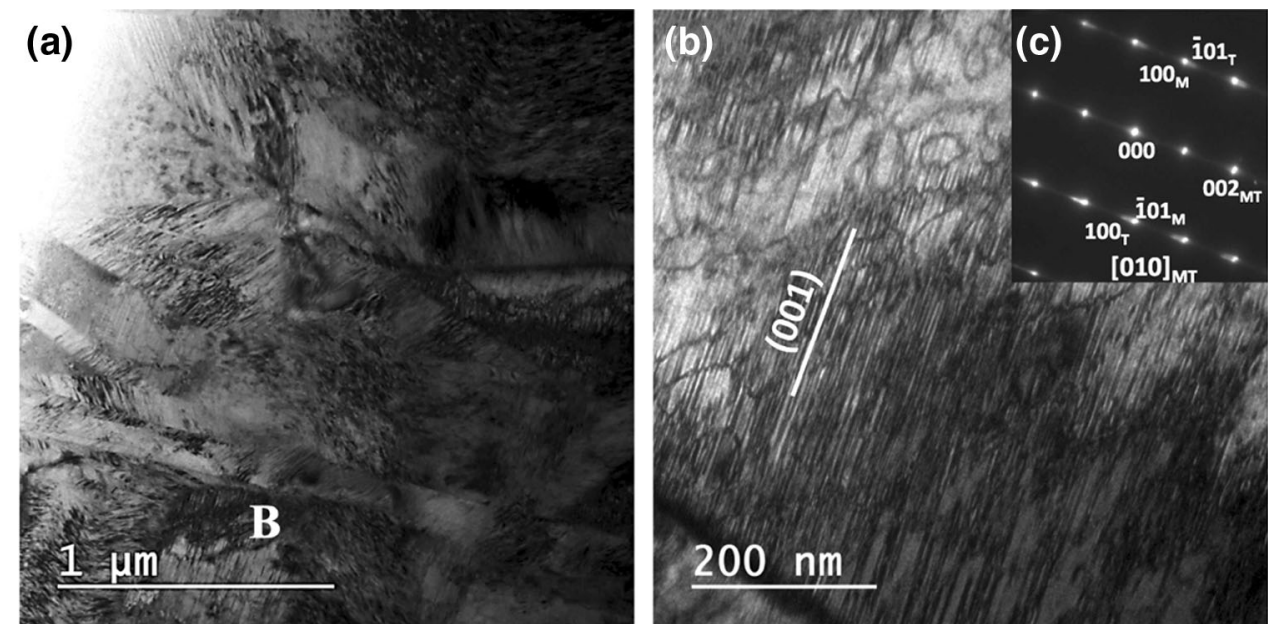


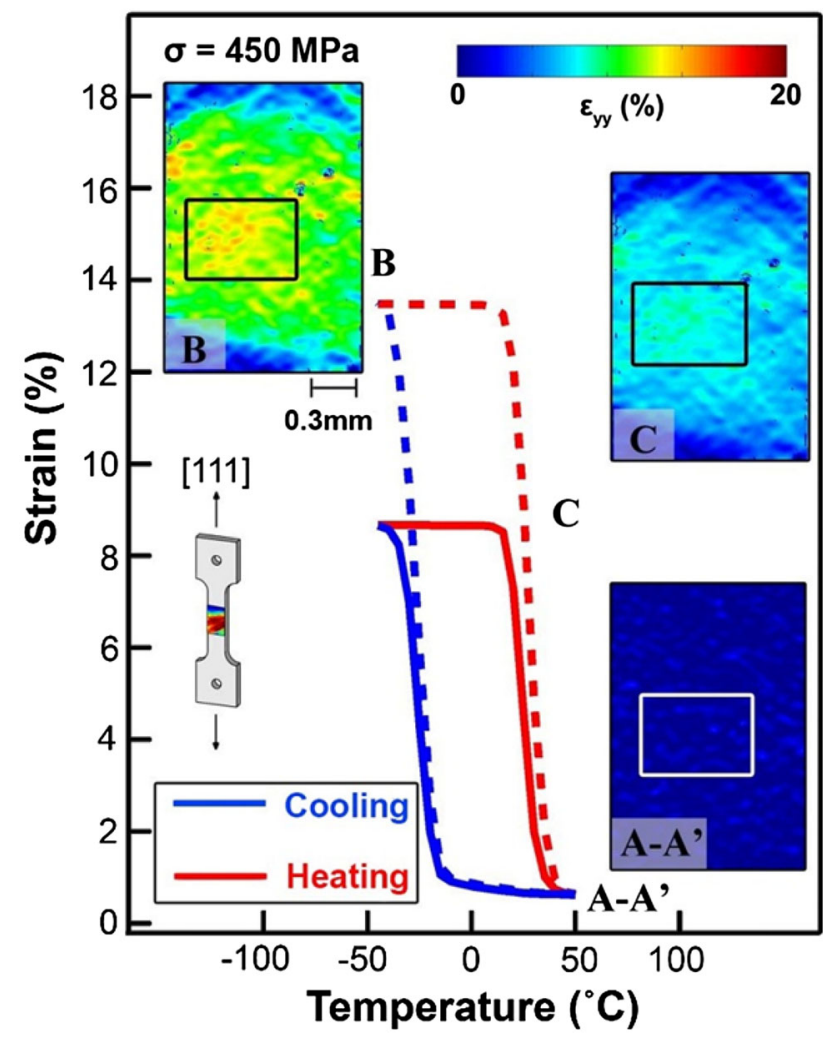

Fig. 15 Isobaric strain-temperature results for the NiTi13Hf alloys oriented in [111] direction under tension. External applied stress is $450 \mathrm{MPa}$. The dashed line represents the results using the smaller domain marked with a rectangle

orientations. There are nearly 60 experiments conducted providing an extensive experimental database. The experimental results were obtained from three types of experiments: (i) shape memory (deform below $M_{\mathrm{f}}$, unload to zero stress, and heat for recovery), (ii) superelasticity (load and unload at constant temperature), and (iii) isobaric temperature cycling (under constant stress). In the shape memory experiments on NiTi13Hf, the specimens were deformed at $-30{ }^{\circ} \mathrm{C}$ and at higher temperatures near $50{ }^{\circ} \mathrm{C}$ for superelasticity. The recoverable strains were in the range $12-22 \%$. The range of experimental results are indicated with error bars. The specimens are from different batches of single crystals with small variations in composition (in both $\mathrm{Ni}$ and $\mathrm{Hf}$ contents) which result in variation of results. These results are very impactful because of the large strains. The transformation strains in tension are very high in [111] orientation with experimental results exceeding the theoretical values in same cases. This is possibly due to additional twinning modes that may be recoverable beyond the phase transformation. The polycrystalline results fall below the [011] strain levels in Fig. 18. In Fig. 19, the NiTi25Hf results are presented for [011]-, [111]-, [3 4 14]-, and [001]-oriented single crystals. All the results given are for compression, except the [111] case which includes tensile results. To be more specific, the compression results are shown for $\mathrm{Ni}_{51.2} \mathrm{Ti}_{23.4} \mathrm{Hf}_{25.4}$ alloys. The tensile results are illustrated for [111] $\mathrm{Ni}_{50.3} \mathrm{Ti}_{25} \mathrm{Hf}_{24.7}$ single crystals. Among the tensile database, the results of the aged cases are marked as triangles. Note that the temperatures in Fig. 19 are far higher than those in Fig. 18.

The most noteworthy results are the following: (i) in isobaric experiments on [111] NiTi25Hf (at a constant stress of $250 \mathrm{MPa}$ ) resulted in strain near 10\%, (Fig. 16) (ii) on [111] NiTi13Hf isobaric tension, the transformation
Fig. 16 The superelastic behavior of [011]

$\mathrm{Ni}_{51.2} \mathrm{Ti}_{23.4} \mathrm{Hf}_{25.4}$ single crystals in compression at $200{ }^{\circ} \mathrm{C}$ is illustrated. The specimen was aged at $550{ }^{\circ} \mathrm{C}$ for $11 \mathrm{~h}$. The local strain-strain behavior (blue curve) was obtained within the rectangular volume, while the overall strain measurement (black curve) was presented by averaging the entire DIC region (Color figure online)

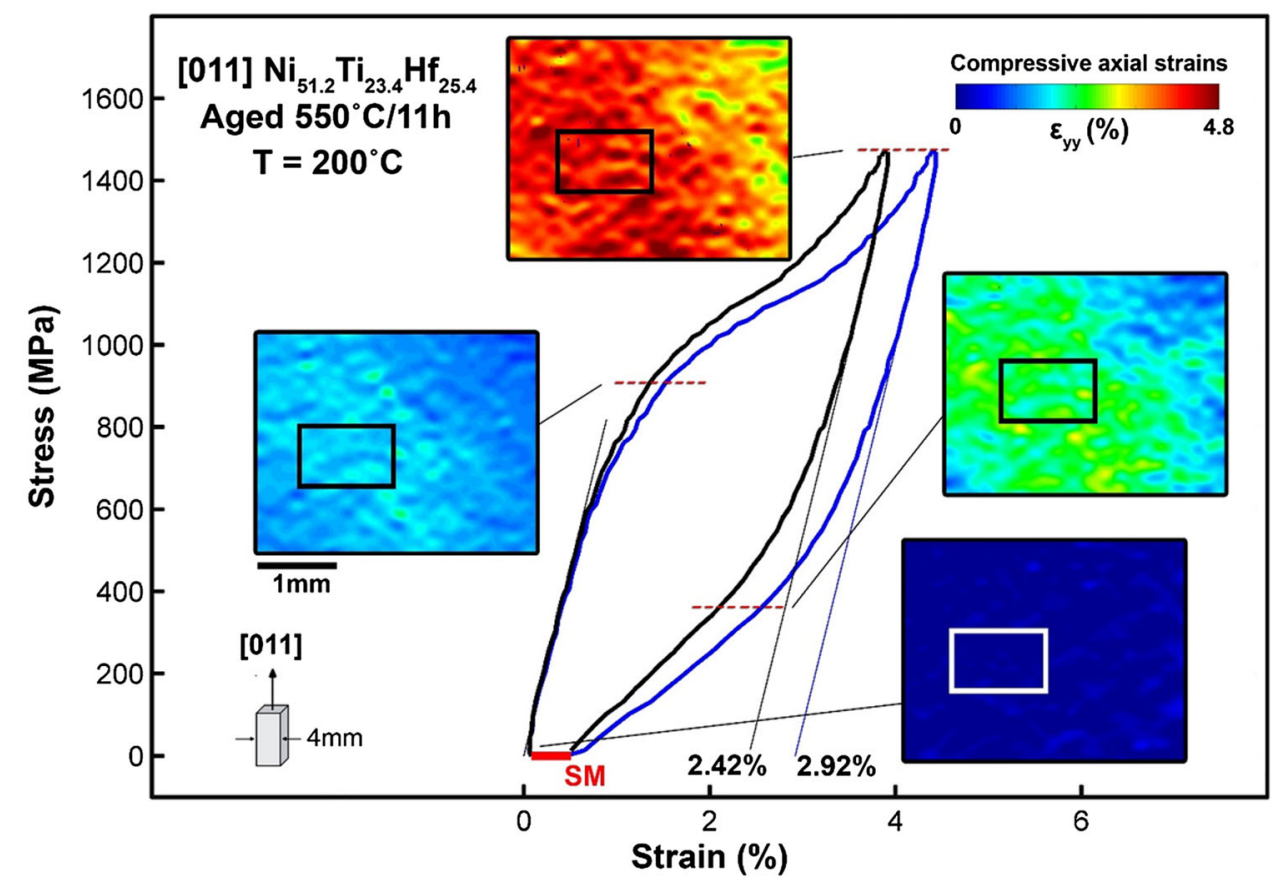


Fig. 17 a Isobaric experiments on [111] $\mathrm{Ni}_{50.3} \mathrm{Ti}_{25} \mathrm{Hf}_{24.7}$ single crystals showing local strains near $9.5 \%$ and transformation (austenite finish) temperatures are near $420{ }^{\circ} \mathrm{C}$. External applied stress is tensile at $250 \mathrm{MPa}$. Strains for both the local (marked with a box on the figure) and global scale (the entire DIC area) are shown. b Comparison of DIC results and the traces of martensite variants showing activation of $\mathrm{V \# 3,} \mathrm{V \# 9,} \mathrm{and} \mathrm{V \# 11} \mathrm{(only} 12$ variants are shown for simplicity). Note that EBSD characterized the loading and side orientation of the sample

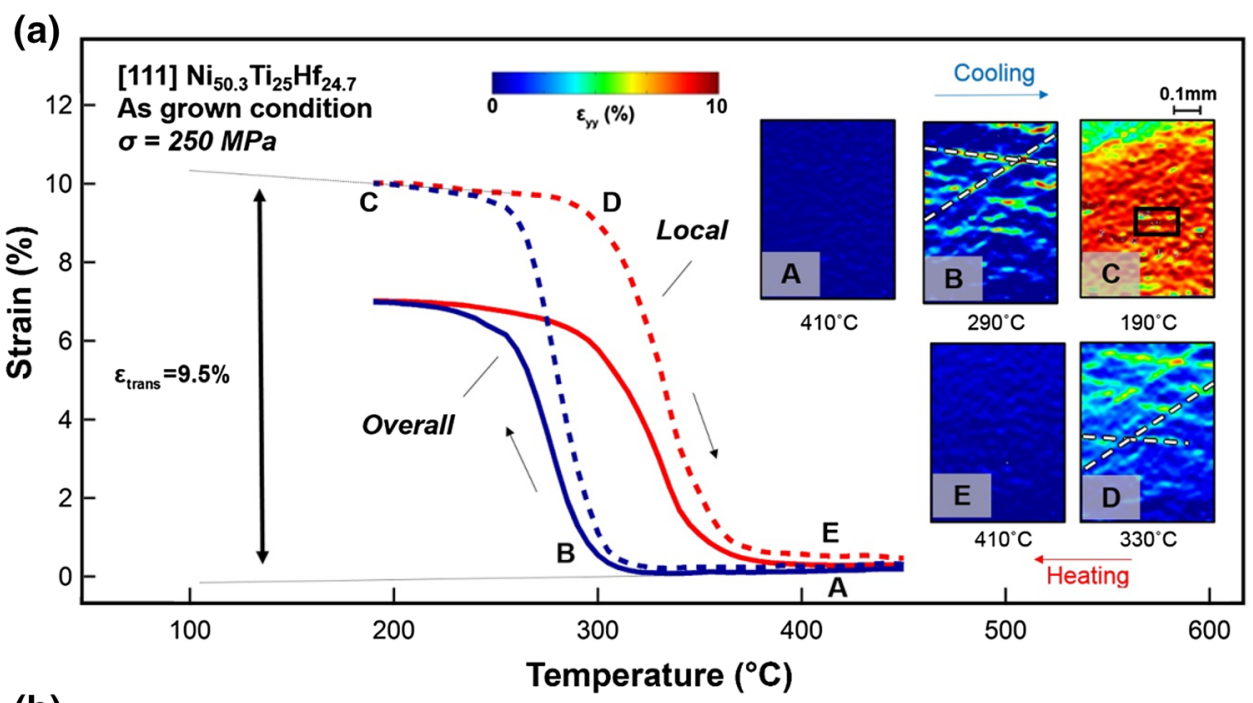

(b)

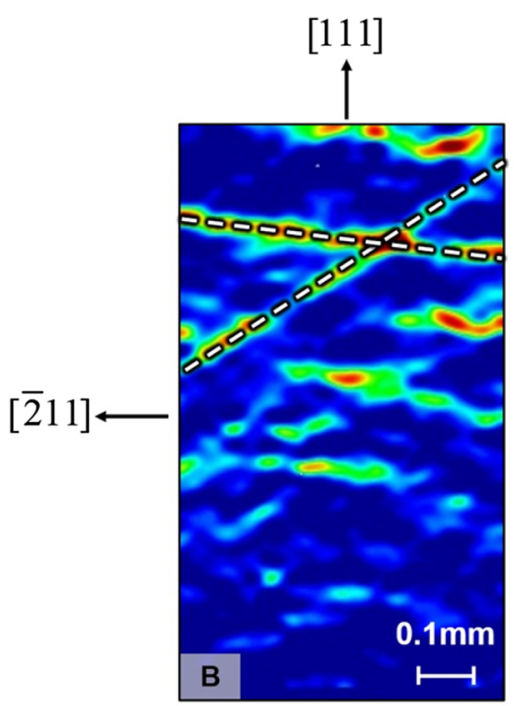

$(0 \overline{1} 1)$

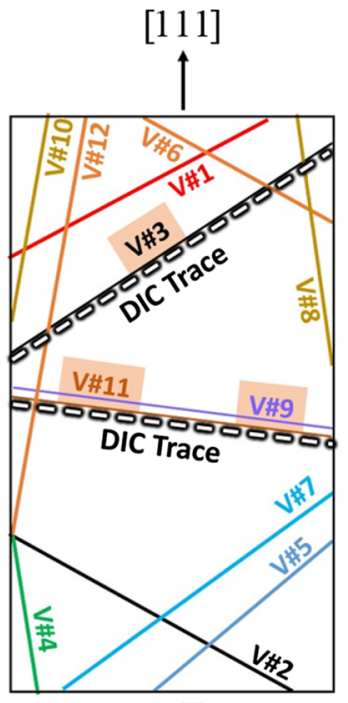

$(0 \overline{1} 1)$ strain was as high as $14 \%$ (Fig. 15), and (iii) in superelasticity experiment on [111] NiTi13Hf under compression, the strain was near 7\% (Fig. 14).

The experimental points are obtained using local strain measurements via digital image correlation (DIC). The details of DIC method can be found in [25, 48, 49]. Local strains determined with DIC technique establish the maximum transformation strains for the specific crystal orientation. The results presented represent the intrinsic maximum transformation strain obtainable along a specific crystal orientation.

The polycrystalline transformation strain is also shown in Figs. 18 and 19 using a micromechanical model [50]. The orientations of the grains are measured using electron back scattering diffraction (EBSD). In the micromechanical model, the transformed martensite is treated as an inhomogeneity embedded in a grain. The internal stress is calculated, upon averaging over multiple active variants, and provides a measure of the overall stress. The overall transformation strains are calculated by considering the transforming inhomogeneity constrained by the surrounding matrix. The grain orientations are measured with EBSD and used as input to the model. In our case, it was found that the polycrystalline grains favored the [011] orientation. An example of EBSD measurements and the local deformation is shown in Fig. 20. The strain fields obtained with DIC were successively overlapped and a direct correlation between transformation strains and grain orientation was then obtained for the polycrystalline specimens. The largest strains were measured for those grain orientations predominantly oriented along the [011] direction in compression. We note that the grain orientations near [011] and [111] poles exhibit the highest shape memory functionality for compression and tension, respectively. The grains near the [001] pole exhibit small strain values in both cases. 


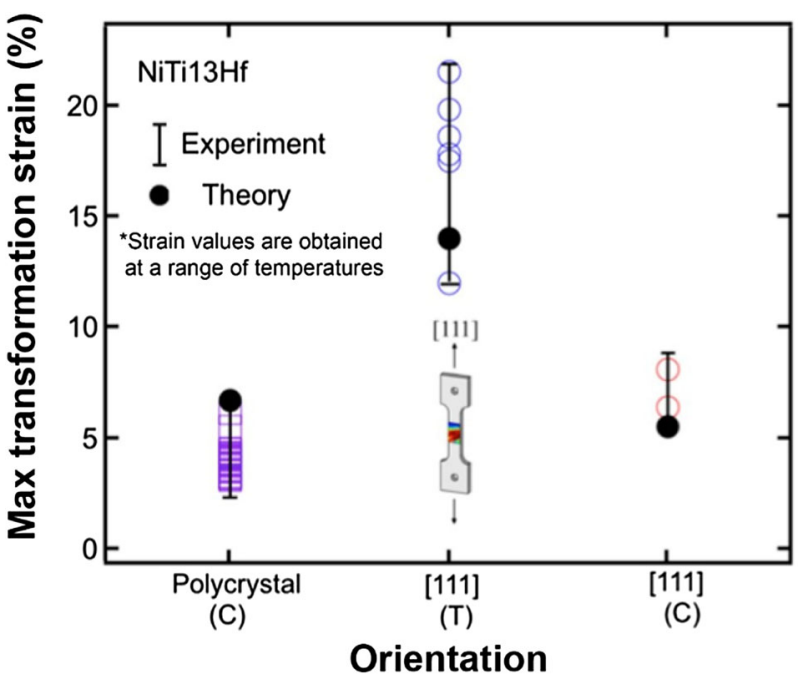

Fig. 18 Maximum transformation strain for NiTi13Hf single crystals and polycrystalline alloy. The compressive results have been presented for polycrystalline and single crystalline oriented along [111] direction. The tensile results have been shown for [111] single crystals as well. The test results were obtained at a range of temperatures

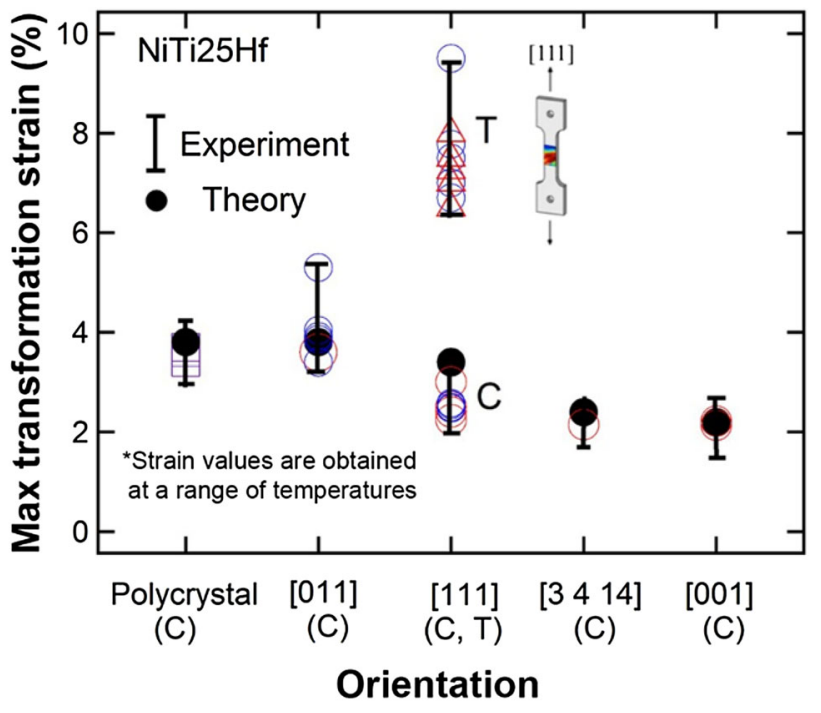

Fig. 19 Maximum transformation strain for the NiTi25Hf polycrystalline alloy and several single crystals. The compression results are shown for $\mathrm{Ni}_{51.2} \mathrm{Ti}_{23.4} \mathrm{Hf}_{25.4}$ alloys. The tensile results of $\mathrm{Ni}_{50.3} \mathrm{Ti}_{25}$ $\mathrm{Hf}_{24.7}$ single crystals oriented in [111] direction are presented. Among the tensile database, the results of the aged cases are illustrated as triangles. The test results were obtained at a range of temperatures

\section{Discussion of Results}

We note that the stress-strain curves for the [111] compression case (Fig. 14) show an inhomogeneous martensitic transformation. A stress plateau typically identified with SMA alloys ensures transformation, while an ascending stress-strain curve reaches the slip stress which results in irreversibility. In this latter case, multiple martensite plates are nucleated which elevates the stress upon deformation. Fortunately, the hardening level (due to possible martensite-slip or martensite-martensite interaction), i.e., the slope, is not sufficiently high to elevate the stresses to create dislocation slip at the macrosacle. Our recent DFT calculations point to very high critical shear stress levels for slip in NiTiHf alloys (CRSS $=614 \mathrm{MPa}$ for NiTi25Hf case), and therefore, these alloys can accommodate higher internal stresses compared to binary NiTi. Austenite-yielding Schmid factors are near 0.5 for the prevailing $<100>\{110\}$ slip system [51] [52] for both [011] and [111] orientations. It is the high critical slip stress that allows orientations such as [011] and [111] to achieve high strains without gross slip deformation. Based on the stress-strain curves, the uniaxial flow stresses, near the $M_{\mathrm{d}}$ temperature, are $1100 \mathrm{MPa}$ and $900 \mathrm{MPa}$ for NiTi13Hf and NiTi25Hf, respectively. These values are higher than the $500 \mathrm{MPa}$ level for binary NiTi [53]. The Md temperature is the temperature above which slip dominates. The $M_{\mathrm{d}}$ temperatures are 110 and $380{ }^{\circ} \mathrm{C}$ for NiTi13Hf and NiTi25Hf, respectively. A linear extrapolation of the high-temperature results should be made for the NiTi25Hf case to compare these results at the same temperature (this results in flow stress exceeding $1600 \mathrm{MPa}$ for the NiTi25Hf case). We note that the critical stress for austenite to martensite transformation is lower than the slip stresses for NiTiHf alloys. When the $A_{\mathrm{f}}$ temperature is of the same order as $M_{\mathrm{d}}$ temperature, this would limit the superelastic window in NiTi25Hf compared to NiTi13Hf. At the same time, the isobaric shape memory functionality of NiTi25Hf is extraordinary, and not affected by the closeness of $A_{\mathrm{f}}-M_{\mathrm{d}}$, as shown in Fig. 17.

Martensite detwinning can result in a single martensite variant that is dominant [21]. The detwinning strain is calculated as an additional transformation strain component. The detwinning strain in tension in NiTi-based alloys is considered to be significant. We have considered all possible twin systems in our calculations and focused on the Type I twinning observed in experiments. Considering Fig. 15, we note that the transformation strain locally is reaching $13 \%$ and this value is consistent with Table 4row 3 . We selected the [111] orientation to give the highest transformation strain in tension based on theory, and our results confirm this finding. Reorientation of martensite occurs as further detwinning develops. In this case, martensite plates containing Type I twins migrate under tensile deformation. In contrast, under compression, this mechanism was not favored resulting in smaller strain magnitudes. We note that the detwinning process can be curtailed due to grain boundaries in polycrystalline alloys.

The results (Fig. 14) show that the unloading modulus of the martensite is higher than the austenite elastic modulus in NiTiHf alloys. This is a topic of current importance 
Fig. 20 EBSD and experimental strain map obtained with high-resolution digital image correlation strain measurements under compression. The strain measurements show that the grains which undergo the largest strains are those orientated close to the [011] orientation. The orientations close to [111] also undergo high strains which are comparable to the [001]oriented grains

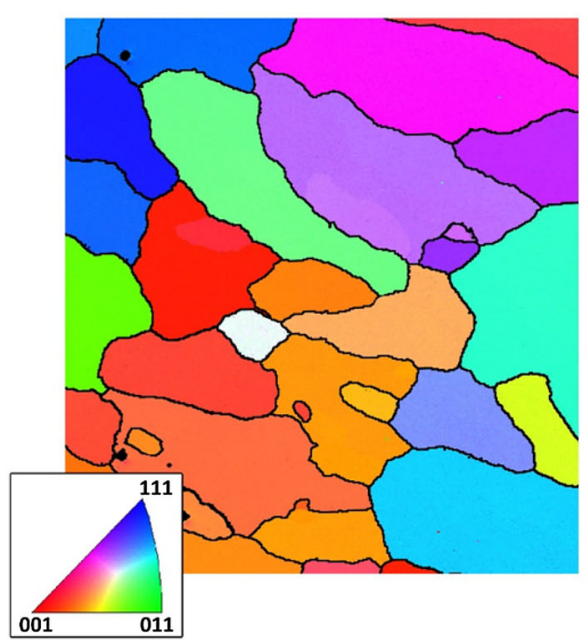

Table 4 Theoretical tensile transformation strains based on cubic to monoclinic model

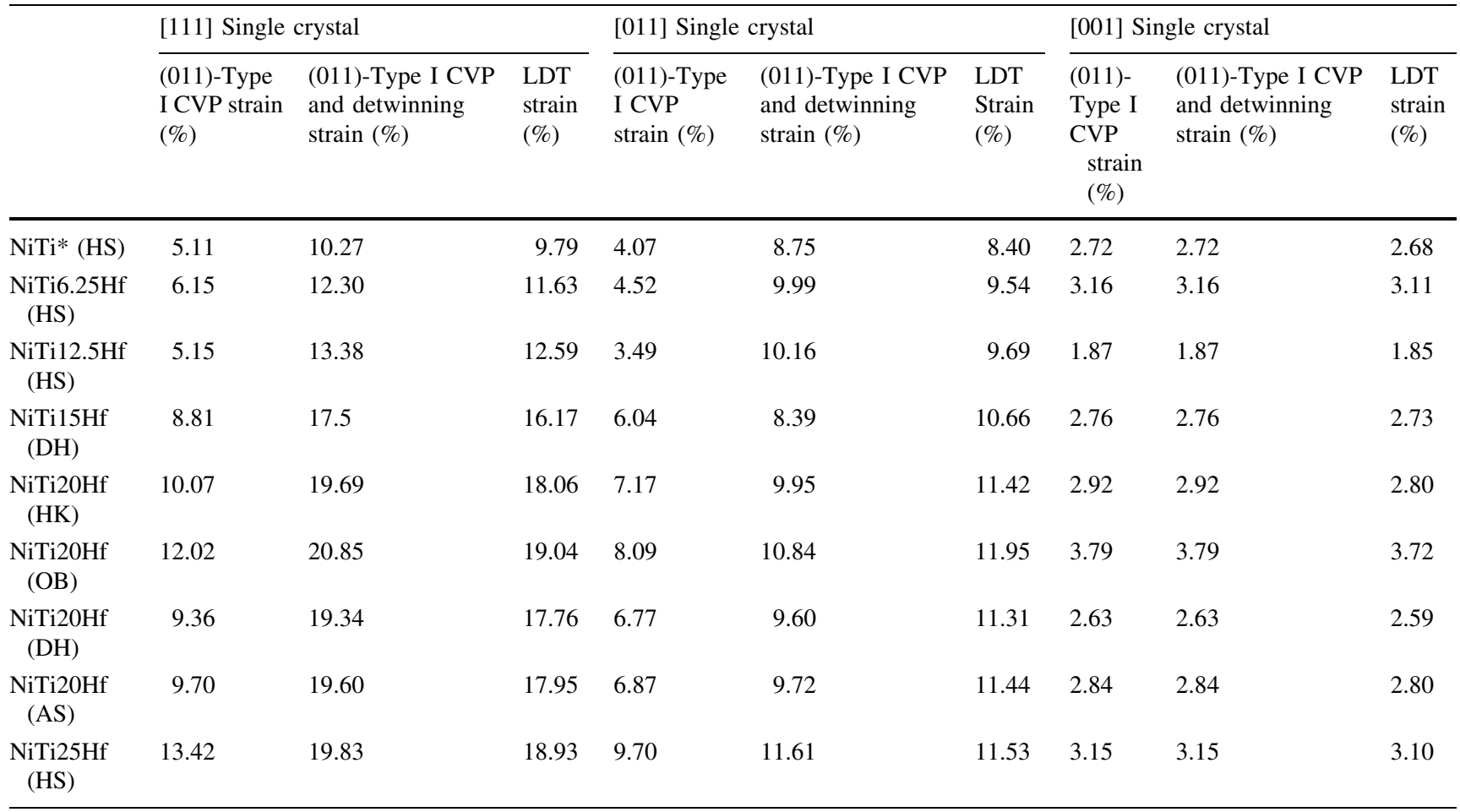

Note that orientations near [111] pole produce strains as high as $19 \%$ in tension for NiTi25Hf

* CVP and CVP detwinning strain for NiTi are for [001]-Type II twin

because there is a misconception about the moduli of the two phases. As noted in our previous work [54], the martensite moduli are higher than austenite moduli. The higher martensite modulus creates favorable fatigue crack growth resistance as noted in early work [49].

The constant stress levels for thermal cycling experiments in NiTi [47] were mostly less than $200 \mathrm{MPa}$, and at higher stress levels, permanent inelastic deformation occurs. The response of strain-temperature is highly nonlinear as seen in Figs. 15 and 17 but at much higher stresses (450 MPa) in NiTi13Hf and $250 \mathrm{MPa}$ in NiTi25Hf. These nonlinear strain-temperature curves point to the strong role of variant-variant interaction, the high levels of stored elastic energy and result in a more gradual transformation upon cooling [47]. Also, a wider hysteresis is noted in NiTiHf alloys (near $60{ }^{\circ} \mathrm{C}$ in Figs. 15 and 17) compared to 
NiTi, and depending on the application (actuator vs damping), small or large hysteresis may be beneficial.

The experimental results clearly show a strong orientation dependence (Figs. 18, 19). The orientations of most interest are the [111] and [011] cases. It is remarkable to observe how the addition of $\mathrm{Hf}$ to $25 \%$ results in a dramatic upswing in the [111] compression theory case (Fig. 3b) which is supported by experiments showing unusually high strains in [111] (Fig. 14). Although the [001] pole has been shown to be of interest in NiTi alloys [22] because of low Schmid factor for slip and good transformation strains in compression, the theoretical predictions showed that the transformation strain in [001] direction in fact decreased with increasing $\mathrm{Hf}$ content. The experimental results summarized in Fig. 19 confirm that [001] pole results in very small transformation strains.

The Clausius-Clapeyron equation has been established based on the experiments, the $\mathrm{d} \sigma / \mathrm{d} T$ values pointed to $14 \mathrm{MPa} /{ }^{\circ} \mathrm{C}$ for NiTi13Hf ([011] orientation), while the slope was $10 \mathrm{MPa} /{ }^{\circ} \mathrm{C}$ for NiTi25Hf. The criteria for superelasticity [55] have been shown to be favored with a lower thermal hysteresis, $A_{\mathrm{f}}-M_{\mathrm{s}}$, lower $\mathrm{d} \sigma / \mathrm{d} T$, and lower transformation stress relative to slip stress. For NiTiHf, the hysteresis levels exceed the values for NiTi, while a higher slip resistance facilitates superelasticity. In that regard, the NiTiHf alloys are similar to high $\mathrm{Ni} 51.5 \mathrm{Ni}-\mathrm{Ti}$ alloys where superelasticity can readily occur [56]. The main difference is that in $51.5 \mathrm{Ni}-\mathrm{Ti}$ alloys, the transformation strains are less than $3 \%$ unlike the NiTiHf alloys where the strains are exceeding $10 \%$. Therefore, the NiTiHf alloys present unique properties in the SMA field.

\section{Conclusions}

The work supports the following:

1. The results show the considerable promise of the NiTiHf alloys. The results point to transformation strains as high as $12 \%$ for the NiTi13Hf which can be suited for applications requiring ultra-high strains. Austenite finish temperatures exceeding $420{ }^{\circ} \mathrm{C}$ were measured for the $25 \mathrm{Hf}$ composition with transformation strain levels near $10 \%$ in tension. The functionality at such high temperatures opens new technological possibilities.

2. The level of theoretical transformation strains based on the cubic to monoclinic model is in general agreement with experimental results on NiTiHf alloys with increasing Hf content. The experimental results show that transformation strains were found to be highest in [111] tension for NiTi13Hf and NiTi25Hf alloys, respectively. Therefore, suitable texturing treatments can produce very favorable alloys in tension. The habit plane orientation obtained from DIC is in perfect agreement with the predicted habit plane variant from theory providing independent support on the calculations of lattice constants and the phenomenological theory.

3. The theoretical transformation strains shift to higher levels as Hf content increases. This is ultimately related to the changes in the lattice constants (most prominently the monoclinic angle is approaching $105.4^{\circ}$ for the $25 \mathrm{Hf}$ case) induced by the increase of Hf content. The polycrystalline alloy transformation strains were also predicted using the EBSD/X-ray diffraction results and a micromechanical analysis. The polycrystal compression specimens have preferred $<011>$ texture and showed experimental (and theoretical) levels comparable to $<011>$ single crystals tested in compression. The transformation strains levels in compression are higher than $6 \%$ which exceeds binary NiTi alloys.

4. Based on the theoretical results, the detwinning strain is much more significant for deformation under tension than under compression. Theoretical transformation strains for detwinned martensite and lattice deformation theory are in general agreement. Because of the high slip resistance of NiTiHf alloys, the transformation can proceed even at high stresses without the propensity of gross slip.

5. The lattice constants measured with selected area diffraction using TEM and the DFT results are in excellent agreement and point to large monoclinic angles which result in large transformation strains. The TEM results confirm the presence of Type I transformation twins and (001) compound twinning. The twin types are the same in aged and solutionized crystals. The results point to blocky precipitates as opposed to lenticular ones rich in $\mathrm{Ni}$ and $\mathrm{Hf}$.

Acknowledgements The work is supported by a National Science Foundation grant NSF CMMI-1333884 which is gratefully acknowledged. Professor Nishida acknowledges the Grant No. 26249090 from the Japanese Society for the Promotion of Science. Prof. Chumlyakov was supported by RSF 14-29-00012.

\section{Appendix 1: Lattice Constant Determination by Density Functional Theory and Transformation of NiTi25Hf}

Lattice constant calculations are demonstrated for the $25 \%$ Hf case in Fig. 21. The first-principles Density Functional Theory (DFT) calculations_-Vienna ab initio Simulations Package (VASP) with the projector augmented wave (PAW) method and the generalized gradient approximation (GGA) [57, 58] were performed. In our calculations, we 


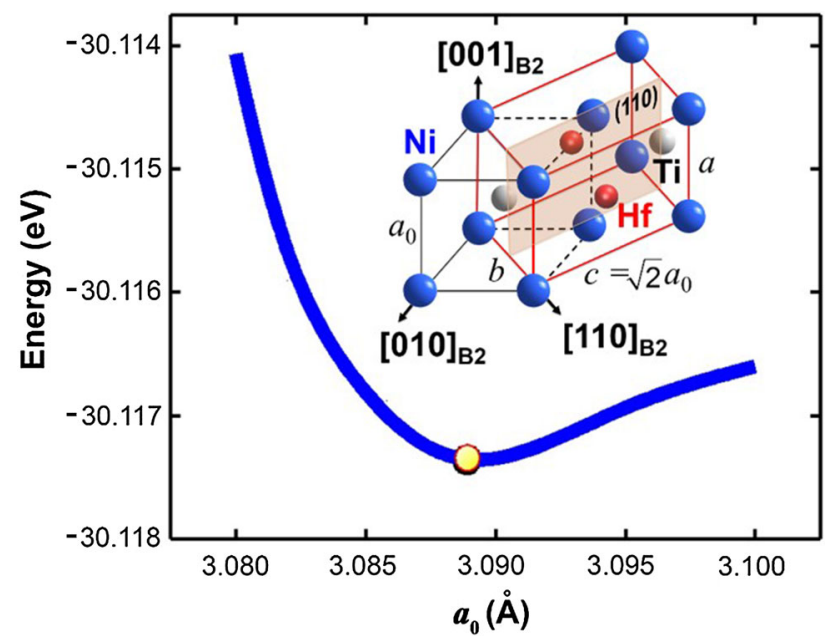

Fig. 21 Energy minimization to obtain the lattice constant of B2 NiTi25Hf. The total energy is reported for 4 atoms in a cell

used a $9 \times 9 \times 9$ Monkhorst-Pack $k$-point meshes for the Brillouion-zone integration to ensure the convergence of results. Ionic relaxation was performed by a conjugate gradient algorithm. The energy cut-off of $360 \mathrm{eV}$ was used for the plane-wave basis set. The total energy was converged to less than $10^{-5} \mathrm{eV}$ per atom. For lattice constant determination, a full internal atom relaxation was allowed for minimizing the total energy of the crystal. For cubic crystal, we obtained the energy variation of the crystal with respect to different lattice parameters in our simulations. The equilibrium lattice constant corresponding to the minimum structural energy (for austenite) was obtained as 3.089 $\AA$. The lattice constants obtained through DFT calculations which are within $2 \%$ of the experimentally observed value. In case of monoclinic NiTiHf, we undertook energy minimization with respect to each of the lattice parameters sequentially. The orthorhombic structure can be derived from the cubic structure by allowing lattice parameters to change for the constant monoclinic angle. This deformation can be expressed in terms of the lattice constant ratios $b / c$ and $a / c$ for a fixed volume.

While the martensitic transformation in equiatomic NiTi has been well studied, that of the NiTiHf is still lacking. We note that the transformation from B2 to B19' phase occurs through an intermediate B19 phase during which the lattice constants and monoclinic angle change. Here, we present the complete energy pathway associated with the martensitic transformation in NiTi25Hf. It is proposed that B2-B19 transformation occurs by the application of a $<110>\{110\}$ basal bilayer shear and shuffle [59]. Further $<110>\{001\}$ nonbasal shear transforms the B19-B19' structure. The shear displacements are shown as horizontal axis in Fig. 22. We observe that during the transformation from $\mathrm{B} 19$ to $\mathrm{B} 19^{\prime}$, the $c$-axis elongation is prominent. Our

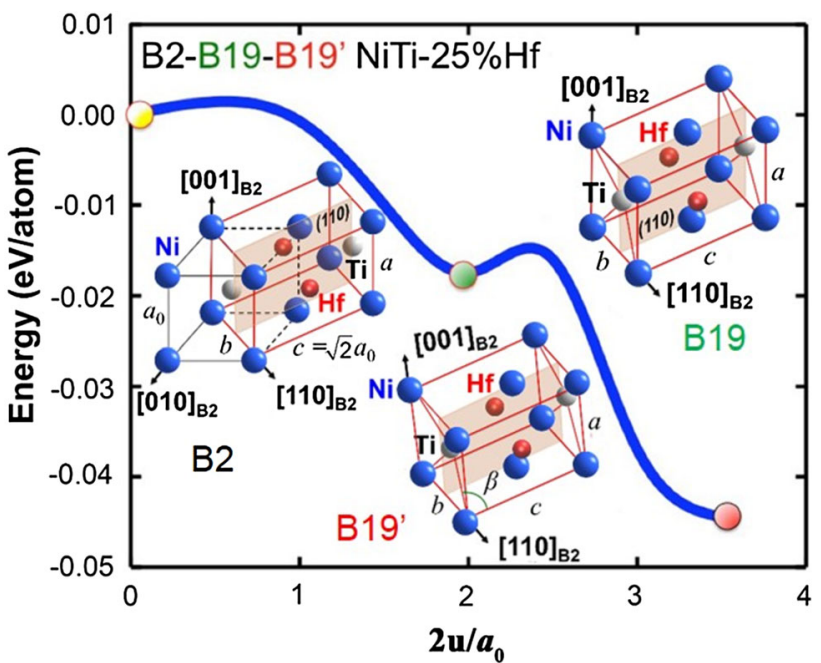

Fig. 22 B2-B19-B19' transformation path of NiTi25Hf (schematics not to scale). The austenitic crystal structure is B2, and energy/atom is given with respect to B2 energy.

first-principles energy calculations confirm that B19' has a lower energy compared to B 19 structure by $25 \mathrm{meV} /$ atom. The energy transformation barrier from $\mathrm{B} 2$ structure to B19 requires overcoming a barrier of $2 \mathrm{meV} / \mathrm{atom}$ and $\mathrm{B} 19-\mathrm{B} 19^{\prime}$ close to $4.6 \mathrm{meV} / \mathrm{atom}$. As stated earlier, the energy barrier between B19 and B19' is small, raising the possibility that B19 could exist in micro-domains. This is beyond the scope of this paper.

\section{References}

1. Duerig TW, Melton K, Stockel D, Wayman C (1990) Engineering aspects of shape memory alloys. Butterworth-Heinemann, Rushden

2. Miyazaki S, Otsuka K, Suzuki Y (1981) Transformation pseudoelasticity and deformation behavior in a Ti-50.6at\% Ni alloy. Scr Metall 15:287-292

3. Hamilton RF, Sehitoglu H, Chumlyakov Y, Maier HJ (2004) Stress dependence of the hysteresis in single crystal NiTi alloys. Acta Mater 52:3383

4. Strnadel B, Ohashi S, Ohtsuka H, Miyazaki S, Ishihara T (1995) Effect of mechanical cycling on the pseudoelasticity characteristics of TiNi and TiNiCu alloys. Mater Sci Eng A 203:187-196

5. Lagoudas DCE (2010) Shape memory alloys. Springer, Berlin

6. Chowdhury P, Sehitoglu H (2016) Significance of slip propensity determination in shape memory alloys. Scr Mater 119:82-87

7. Angst RD, Thoma EP, Kao YM (1995) The effect of hafnium content on the transformation temperatures of $\mathrm{Ni}_{[49]} \mathrm{Ti}_{[51-x]} \mathrm{Hf}_{[x]}$ shape memory alloys. EDP Sciences, Les Ulis

8. Han XD, Zou WH, Wang R, Zhang Z, Yang DZ (1996) Structure and substructure of martensite in a $\mathrm{Ti}_{36.5} \mathrm{Ni}_{48.5} \mathrm{Hf}_{15}$ high temperature shape memory alloy. Acta Mater 44:3711-3721

9. Potapov PL, Shelyakov AV, Gulyaev AA, Svistunov EL, Matveeva NM, Hodgson D (1997) Effect of Hf on the structure of $\mathrm{Ni}$-Ti martensitic alloys. Mater Lett 32:247-250

10. Wu KH, Pu ZJ, Gao Y, Wayman CM (1998) Study of NiTi-Hf and NiTi-Zr high-temperature shape memory alloys. Proceedings of the 1996 international conference on displacive phase 
transformations and their applications in materials engineering, May 8, 1996-May 9, 1996. Minerals, Metals \& Materials Soc (TMS), Urban, pp 285-290

11. Zheng YF, Cai W, Zhang JX, Wang YQ, Zhao LC, Ye HQ (1998) High-resolution electron microscopy study on the substructure of Ti-Ni-Hf B19' Martensite. Mater Lett 36:142-147

12. Thoma PE, Boehm JJ (1999) Effect of composition on the amount of second phase and transformation temperatures of $\mathrm{Ni}_{x} \mathrm{Ti}_{90-x} \mathrm{Hf}_{10}$ shape memory alloys. Mater Sci Eng A 273-275:385-389

13. Meng XL, Zheng YF, Wang Z, Zhao LC (2000) Effect of aging on the phase transformation and mechanical behavior of $\mathrm{Ti}_{36}$ $\mathrm{Ni}_{49} \mathrm{Hf}_{15}$ high temperature shape memory alloy. Scr Mater 42:341-348

14. Dalle F, Perrin E, Vermaut P, Masse M, Portier R (2002) Interface mobility in $\mathrm{Ni}_{49.8} \mathrm{Ti}_{42.2} \mathrm{Hf}_{8}$ shape memory alloy. Acta Mater $50: 3557$

15. Santamarta R, Seguí C, Pons J, Cesari E (1999) Martensite stabilisation in $\mathrm{Ni}_{50} \mathrm{Ti}_{32.2} \mathrm{Hf}_{17.7}$. Scr Mater 41:867-872

16. Wang J, Sehitoglu H (2014) Modelling of martensite slip and twinning in NiTiHf shape memory alloys. Philos Mag 94:2297-2317

17. Wang J, Sehitoglu H, Maier HJ (2014) Dislocation slip stress prediction in shape memory alloys. Int J Plast 54:247-266

18. Ma J, Karaman I, Noebe RD (2010) High temperature shape memory alloys. Int Mater Rev 55:257-315

19. Stebner AP, Bigelow GS, Jin Y, Shukla DP, Saghaian SM, Rogers R et al (2014) Transformation strains and temperatures of a nickel-titanium-hafnium high temperature shape memory alloy. Acta Mater 76:40-53

20. Karaca H, Saghaian S, Basaran B, Bigelow G, Noebe R, Chumlyakov Y (2011) Compressive response of nickel-rich NiTiHf high-temperature shape memory single crystals along the [111] orientation. Scr Mater 65:577-580

21. Sehitoglu H, Hamilton R, Canadinc D, Zhang XY, Gall K, Karaman I et al (2003) Detwinning in NiTi alloys. Metall Mater Trans A 34:5

22. Sehitoglu H, Karaman I, Anderson R, Zhang X, Gall K, Maier H et al (2000) Compressive response of NiTi single crystals. Acta Mater 48:3311-3326

23. Miyazaki S, Kimura S, Takei F, Miura T, Otsuka K, Suzuki Y (1983) Shape memory effect and pseudoelasticity in a Ti-Ni single crystal. Scr Metall 17:1057-1062

24. Matsumoto O, Miyazaki S, Otsuka K, Tamura H (1987) Crystallography of martensitic transformation in TiNi single crystals. Acta Metall 35:2137-2144

25. Wu Y, Patriarca L, Li G, Sehitoglu H, Soejima Y, Ito T et al (2015) Shape memory response of polycrystalline $\mathrm{NiTi}_{12.5} \mathrm{Hf}$ alloy: transformation at small scales. Shap Mem Superelast 1:387-397

26. Thoma P, Zhang C, Boehm JJ, Zee RH (1997) The effect of hafnium content and cycling under an applied axial stress on the creep and martensite strain of NiTi based shape memory alloy wires. J Phys IV Fr 7:C5-483-C5-8

27. Santamarta R, Segui C, Pons J et al (1999) Martensite stabilisation in $\mathrm{Ni}_{[50]} \mathrm{Ti}_{[32.2]} \mathrm{Hf}_{[17.7]}$. Elsevier, Kidlington

28. Kockar B, Karaman I, Kim J, Chumlyakov Y (2006) A method to enhance cyclic reversibility of NiTiHf high temperature shape memory alloys. Scr Mater 54:2203-2208

29. Profiles Material (2010) Materials and design, 2nd edn. Butterworth-Heinemann, Oxford, pp 194-249

30. Chantz MD, David AM (2012) Thermomechanical training and characterization of $\mathrm{Ni}-\mathrm{Ti}-\mathrm{Hf}$ and $\mathrm{Ni}-\mathrm{Ti}-\mathrm{Hf}-\mathrm{Cu}$ high temperature shape memory alloys. Smart Mater Struct 21:065020

31. Coughlin DR, Phillips PJ, Bigelow GS, Garg A, Noebe RD, Mills MJ (2012) Characterization of the microstructure and mechanical properties of a ${ }_{50.3} \mathrm{Ni}-{ }_{29.7} \mathrm{Ti}-{ }_{20} \mathrm{Hf}$ shape memory alloy. Scr Mater 67:112-115

32. Santamarta R, Arróyave R, Pons J, Evirgen A, Karaman I, Karaca $\mathrm{H}$ et al (2013) TEM study of structural and microstructural characteristics of a precipitate phase in Ni-rich $\mathrm{Ni}-\mathrm{Ti}-\mathrm{Hf}$ and $\mathrm{Ni}-$ Ti-Zr shape memory alloys. Acta Mater 61:6191-6206

33. Wang J, Sehitoglu H (2014) Dislocation slip and twinning in Nibased L12 type alloys. Intermetallics 52:20-31

34. Gall K, Sehitoglu H, Chumlyakov YI, Kireeva IV (1999) Tension-compression asymmetry of the stress-strain response in aged single crystal and polycrystalline NiTi. Acta Mater 47:1203-1217

35. Carroll J, Abuzaid W, Lambros J, Sehitoglu H (2010) An experimental methodology to relate local strain to microstructural texture. Rev Sci Instrum 81:083703

36. Efstathiou C, Sehitoglu H, Carroll J, Lambros J, Maier HJ (2008) Full-field strain evolution during intermartensitic transformations in single-crystal NiFeGa. Acta Mater 56:3791-3799

37. Patriarca L, Wu Y, Sehitoglu H, Chumlyakov YI (2016) High temperature shape memory behavior of $\mathrm{Ni}_{50.3} \mathrm{Ti}_{25} \mathrm{Hf}_{24.7}$ single crystals. Scr Mater 115:133-136

38. Wu Y, Patriarca L, Sehitoglu H, Chumlyakov Y (2016) Ultrahigh tensile transformation strains in new $\mathrm{Ni}_{50.5} \mathrm{Ti}_{36.2} \mathrm{Hf}_{13.3}$ shape memory alloy. Scr Mater 118:51-54

39. Patriarca L, Sehitoglu H, Panchenko EY, Chumlyakov YI (2016) High-temperature functional behavior of single crystal $\mathrm{Ni}_{51.2}$ $\mathrm{Ti}_{23.4} \mathrm{Hf}_{25.4}$ shape memory alloy. Acta Mater 106:333-343

40. Otsuka K, Sawamura T, Shimizu K (1971) Crystal structure and internal defects of equiatomic TiNi martensite. Phys Status Solidi A 5:457

41. Karaca HE, Saghaian SM, Ded G, Tobe H, Basaran B, Maier HJ et al (2013) Effects of nanoprecipitation on the shape memory and material properties of an Ni-rich NiTiHf high temperature shape memory alloy. Acta Mater 61:7422-7431

42. Benafan O, Garg A, Noebe RD, Bigelow GS, Padula Ii SA, Gaydosh DJ et al (2014) Mechanical and functional behavior of a Ni-rich $\mathrm{Ni}_{50.3} \mathrm{Ti}_{29.7} \mathrm{Hf}_{20}$ high temperature shape memory alloy. Intermetallics 50:94-107

43. Saburi T, Nenno S (1981) The shape memory effect and related phenomena. In: Solid to solid phase transformations. pp 1455-1479

44. Bhattacharya K (2003) Microstructure of martensite: why it forms and how it gives rise to the shape-memory effect. Oxford University Press, Oxford

45. Nishida M, Nishiura T, Kawano H, Inamura T (2012) Self-accommodation of B19' Martensite in $\mathrm{Ti}-\mathrm{Ni}$ shape memory alloys-part I. Morphological and crystallographic studies of the variant selection rule. Philos Mag 92:2215-2233

46. Nishida M, Wayman CM, Chiba A (1988) Electron microscopy studies of the martensitic transformation in an aged Ti-51 at \% Ni shape memory alloy. Metallography 21:275-291

47. Sehitoglu H, Hamilton R, Maier HJ, Chumlyakov Y (2004) Hysteresis in NiTi alloys. EDP Sciences, Frejus, p 3

48. Patriarca L, Sehitoglu H (2015) High-temperature superelasticity of $\mathrm{Ni}_{50.6} \mathrm{Ti}_{24.4} \mathrm{Hf}_{25.0}$ shape memory alloy. Scr Mater 101:12-15

49. Wu Y, Ojha A, Patriarca L, Sehitoglu H (2015) Fatigue crack growth fundamentals in shape memory alloys. Shap Mem Superelast $1: 18-40$

50. Gall K, Sehitoglu H (1999) The role of texture in tension-compression asymmetry in polycrystalline NiTi. Int J Plast 15:69-92

51. Surikova NS, Chumlyakov YI (2000) Mechanisms of plastic deformation of the titanium nickelide single crystals. Phys Met Metall 89:196

52. Ezaz T, Wang J, Sehitoglu H, Maier HJ (2013) Plastic deformation of NiTi shape memory alloys. Acta Mater 61:67-78

53. Gall K, Sehitoglu H, Chumlykov YI, Kireeva IV, Maier HJ (1999) The influence of aging on critical transformation stress 
levels and martensite start temperatures in NiTi: part II-discussion of experimental results. Trans ASME J Eng Mater Technol 121:28-37

54. Wang J, Sehitoglu H (2014) Martensite modulus dilemma in monoclinic NiTi-theory and experiments. Int J Plast 61:17-31

55. Liu Y, Galvin SP (1997) Criteria for pseudoelasticity in nearequiatomic NiTi shape memory alloys. Acta Mater 45:4431-4439

56. Sehitoglu H, Jun J, Zhang X, Karaman I, Chumlyakov Y, Maier HJ et al (2001) Shape memory and pseudoelastic behavior of
$51.5 \% \mathrm{Ni}-\mathrm{Ti}$ single crystals in solutionized and overaged state. Acta Mater 49:3609-3620

57. Kresse G, Furthmüller J (1996) Efficient iterative schemes for ab initio total-energy calculations using a plane-wave basis set. Phys Rev B 54:11169-11186

58. Kresse G, Hafner J (1993) Ab initio molecular dynamics for open-shell transition metals. Phys Rev B 48:13115

59. Wang J, Sehitoglu H (2012) Resolving quandaries surrounding NiTi. Appl Phys Lett 101:081907 